\title{
Sustainable management of river oases along the Tarim River (SuMaRiO) in Northwest China under conditions of climate change
}

\author{
C. Rumbaur $^{1}$, N. Thevs ${ }^{2,18}$, M. Disse ${ }^{1}$, M. Ahlheim ${ }^{3}$, A. Brieden ${ }^{4}$, B. Cyffka ${ }^{5}$, D. Duethmann ${ }^{6}$, T. Feike ${ }^{7}$, \\ O. Frör ${ }^{8}$, P. Gärtner ${ }^{9}$, Ü. Halik ${ }^{5}$, J. Hill ${ }^{10}$, M. Hinnenthal ${ }^{4}$, P. Keilholz ${ }^{1}$, B. Kleinschmit ${ }^{9}$, V. Krysanova ${ }^{11}$,

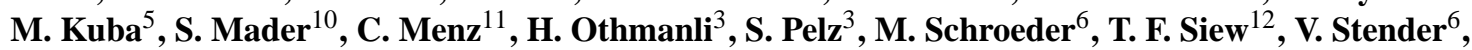 \\ K. Stahr ${ }^{3}$, F. M. Thomas ${ }^{10}$, M. Welp ${ }^{13}$, M. Wortmann ${ }^{11}$, X. Zhao ${ }^{3}$, X. Chen ${ }^{14}$, T. Jiang ${ }^{15}$, J. Luo ${ }^{16}$, \\ H. Yimit ${ }^{17}$, R. Yu ${ }^{14}$, X. Zhang ${ }^{14}$, and C. Zhao ${ }^{14}$ \\ ${ }^{1}$ Technical University Munich, Munich, Germany \\ ${ }^{2}$ Ernst Moritz Arndt University of Greifswald, Greifswald, Germany \\ ${ }^{3}$ University of Hohenheim, Hohenheim, Germany \\ ${ }^{4}$ Universität der Bundeswehr Muenchen, Munich, Germany \\ ${ }^{5}$ Catholic University of Eichstätt-Ingolstadt, Eichstätt, Germany \\ ${ }^{6}$ GFZ German Research Centre for Geosciences, Potsdam, Germany \\ ${ }^{7}$ Federal Research Centre for Cultivated Plants, Kleinmachnow, Germany \\ ${ }^{8}$ Universität Landau, Landau, Germany \\ ${ }^{9}$ Technical University Berlin, Berlin, Germany \\ ${ }^{10}$ University of Trier, Trier, Germany \\ ${ }^{11}$ Potsdam Institute for Climate Impact Research, Potsdam, Germany \\ ${ }^{12}$ Johann Wolfgang Goethe University of Frankfurt, Frankfurt, Germany \\ ${ }^{13}$ Eberswalde University for Sustainable Development, Eberswalde, Germany \\ ${ }^{14}$ Xinjiang Institute of Geography and Ecology, Chinese Academy of Sciences, Urumqi, China \\ ${ }^{15}$ National Climate Center, Beijing, China \\ ${ }^{16}$ Research Center for China's Borderland History and Geography, Chinese Academy of Social Sciences, \\ Beijing, China \\ ${ }^{17}$ Xinjiang Normal University, Urumqi, China \\ ${ }^{18}$ World Agroforestry Center, Bishkek, Kyrgyzstan
}

Correspondence to: C. Rumbaur (christian.rumbaur@tum.de) and N. Thevs (niels.thevs@uni-greifswald.de)

Received: 31 August 2014 - Published in Earth Syst. Dynam. Discuss.: 13 October 2014

Revised: 24 December 2014 - Accepted: 7 January 2015 - Published: 9 March 2015

\begin{abstract}
The Tarim River basin, located in Xinjiang, NW China, is the largest endorheic river basin in China and one of the largest in all of Central Asia. Due to the extremely arid climate, with an annual precipitation of less than $100 \mathrm{~mm}$, the water supply along the Aksu and Tarim rivers solely depends on river water. This is linked to anthropogenic activities (e.g., agriculture) and natural and semi-natural ecosystems as both compete for water. The ongoing increase in water consumption by agriculture and other human activities in this region has been enhancing the competition for water between human needs and nature. Against this background, 11 German and 6 Chinese universities and research institutes have formed the consortium SuMaRiO (Sustainable Management of River Oases along the Tarim River; http://www.sumario.de), which aims to create a holistic picture of the availability of water resources in the Tarim River basin and the impacts on anthropogenic activities and natural ecosystems caused by the water distribution within the Tarim River basin. On the basis of the results from field studies and modeling approaches as well as from suggestions by the relevant regional stakeholders, a decision support tool (DST) will be implemented that will then assist stakeholders in balancing the competition for water,
\end{abstract}


acknowledging the major external effects of water allocation to agriculture and to natural ecosystems. This consortium was formed in 2011 and is funded by the German Federal Ministry of Education and Research. As the data collection phase was finished this year, the paper presented here brings together the results from the fields from the disciplines of climate modeling, cryology, hydrology, agricultural sciences, ecology, geoinformatics, and social sciences in order to present a comprehensive picture of the effects of different water availability schemes on anthropogenic activities and natural ecosystems along the Tarim River. The second objective is to present the project structure of the whole consortium, the current status of work (i.e., major new results and findings), explain the foundation of the decision support tool as a key product of this project, and conclude with application recommendations for the region. The discharge of the Aksu River, which is the major tributary of the Tarim, has been increasing over the past 6 decades. From 1989 to 2011, agricultural area more than doubled: cotton became the major crop and there was a shift from small-scale to large-scale intensive farming. The ongoing increase in irrigated agricultural land leads to the increased threat of salinization and soil degradation caused by increased evapotranspiration. Aside from agricultural land, the major natural and semi-natural ecosystems are riparian (Tugai) forests, shrub vegetation, reed beds, and other grassland, as well as urban and peri-urban vegetation. Within the SuMaRiO cluster, focus has been set on the Tugai forests, with Populus euphratica as the dominant tree species, because these forests belong to the most productive and species-rich natural ecosystems of the Tarim River basin. At sites close to the groundwater, the annual stem diameter increments of Populus euphratica correlated with the river runoffs of the previous year. However, the natural river dynamics cease along the downstream course and thus hamper the recruitment of Populus euphratica. A study on the willingness to pay for the conservation of the natural ecosystems was conducted to estimate the concern of the people in the region and in China's capital. These household surveys revealed that there is a considerable willingness to pay for conservation of the natural ecosystems, with mitigation of dust and sandstorms considered the most important ecosystem service. Stakeholder dialogues contributed to creating a scientific basis for a sustainable management in the future.

\section{Introduction}

The Tarim River basin is located in Xinjiang, Northwest China. It is bordered by the mountain ranges of the Tian Shan in the north, Kunlun in the south, and Pamir in the west. The Taklamakan Desert dominates the basin with the Tarim River flowing along its northern rim. The Tarim River forms in the city of Alar through the confluence of the Yarkant River from the west, Hotan River from the south, and Aksu River from the north (Fig. 2). The latter river constitutes about $80 \%$ of the Tarim River's discharge.

Due to the extremely arid climate, with an annual precipitation of less than $100 \mathrm{~mm}$ and a potential evaporation of about $2000 \mathrm{~mm}$ per year, the water supply along the Aksu and Tarim rivers solely depends on river water. This applies to anthropogenic ecosystems (e.g., agricultural land and urban and peri-urban vegetation) as well as for natural ecosystems (riparian forests and vegetation), causing a competition for water between those ecosystems. The region has been inhabited for several centuries and some of the oldest oases in Asia are located in the Tarim River basin. For 6 decades the Chinese government has been promoting the development of the western provinces of China. The demographic development and socioeconomic change has led to a rapid change of landuse systems in the Tarim River basin over recent decades and has substantially affected the quantity and quality of arable soil, surface water, and groundwater. These changes in soil and water affect the natural vegetation as well as crop production (Bohnet et al., 1998, 1999; Hoppe et al., 2006).

Increase settlement in this region has enhanced the competition for water between human needs and nature. Furthermore, there is a classical upstream-downstream conflict along the Tarim and its tributaries similar to other river basins of Central Asia (Chriacy-Wantrup, 1985; Giese et al., 1998, see CAWA, 2013).

Against this background, 11 German and 6 Chinese universities and research institutes have formed the consortium SuMaRiO (Sustainable Management of River Oases along the Tarim River; http://www.sumario.de). This consortium was formed in 2011 and is funded by the German Federal Ministry of Education and Research. As the data collection phase finished this year, in the next steps of the project we aim to compile results from the fields of climate modeling, cryology, hydrology, agricultural sciences, ecology, geoinformatics and social sciences in order to present a comprehensive understanding of the effects of different water availability schemes on anthropogenic activities and on the natural ecosystems. The effects on the natural ecosystems are captured through the investigation and evaluation of their ecosystem services (MEA, 2005).

In the current project, agricultural land, riparian forests, and urban and peri-urban vegetation are the ecosystems under study. These ecosystems are the basis for ecosystem services which contribute significantly to people's wellbeing 
(TEEB, 2010; ELD, 2013). Basic materials necessary for a viable livelihood, such as food, raw materials for clothing, natural medicine, and income are generated by regional ecosystems. To meet these societal demands, mainly to secure the incomes of the inhabitants of the region, people shape ecosystems to meet their needs. Hydrology is influenced by humans directly, by building reservoirs and canals as well as indirectly by land-use changes (e.g., turning forests and shrubland into agricultural fields which leads to increased water extraction from river and related evapotranspiration).

The existence and maintenance of the different ecosystems are substantial for the people living in the region. Ecosystems and hydrology are closely linked to each other. Using a decision support tool, a linkage between hydrology and ecosystem services will be constructed and decision makers will be able to build an integrated image of the whole region.

The first objective of this paper is to bring together results from the fields of climate modeling, cryology, hydrology, agricultural sciences, ecology, geoinformatics, and social sciences in order to present a comprehensive understanding of the effects of different water availability schemes on anthropogenic activities and on the natural ecosystems along the Tarim River. The second objective is to present the project structure of the whole consortium and the current status of work (i.e., major new results and findings), to explain the foundation of the decision support tool as a key product of this project, and to conclude with application recommendations for the region.

\section{Project description and research sites}

Current management of land and water has resulted in massive environmental and social problems in the region. Large areas with agricultural soil have become unusable through salinization, floodplain vegetation has vastly receded, and important ecosystem services such as attenuating dust and sand storms by vegetation have been severely diminished or completely lost. The Chinese government has realized the immense ecological-economic problems and has tested some mitigating measures, e.g., ecological water transfers. What is lacking are sustainable approaches and measures considering the complete land and water management system with its ecosystem services in an integrated way and taking into account the diverse problem perceptions of the stakeholders.

The aim is to keep the balance between ecosystem services and economic benefits for sustainable development. The protection and utilization of the natural ecosystems and water use have to be brought in equilibrium. The central question is how to manage land use with irrigation agriculture as the largest water consumer under a changing water availability due to climate change. The project is the coordinating project of 12 global projects of the Sustainable Land Man- agement Program of the German Federal Ministry of Education and Research within the GLUES project (Global Assessment of Land Use Dynamics, Greenhouse Gas Emissions and Ecosystem Services) (Eppink et al., 2012) (Fig. 1).

The overall goal of SuMaRiO is to support oasis management along the Tarim River under conditions of climatic and societal change by (1) developing methods for analyzing ecosystem services and integrating them into land and water management strategies of oases and riparian forests; (2) involving stakeholders in the research process to integrate their knowledge and perceptions of problems into the scientific process; (3) developing tools with Chinese decision makers that illustrate the ecological and socioeconomic consequences of their decisions in a changing world; (4) introducing participatory approaches into the development of sustainable management structures; (5) jointly identifying options for optimizing economic, ecological, and societal utility.

The SuMaRiO project is structured into five work blocks (WB): WB 1: organization - project coordination, scenario management, stakeholder dialogue, data management; WB 2: regional climate change and discharge of Tarim tributaries - monitoring and modeling of cryosphere, regional climate scenarios and medium-term forecast of precipitation, climate change impact on water discharge; WB 3: sustainable water and land-use management in the Tarim Basin - water demands and water quality on the plot scale $\left(0.1 \mathrm{~km}^{2}\right)$, hydrology, salinity, and biomass production on the local scale $\left(10 \mathrm{~km}^{2}\right)$, upscaling to the regional scale $\left(200 \mathrm{~km}^{2}\right)$, modeling of the water balance along the Tarim River $\left(1000 \mathrm{~km}^{2}\right)$; WB 4: ecosystem services and ecosystem functions along the Tarim River - in riparian ecosystems, non-irrigated land-use systems, and urban and peri-urban oasis vegetation; WB 5: multi-level socioeconomic assessment of ecosystem services and implementation tools - multi-level economic system assessment; transdisciplinary assessment of ecosystem services for urban areas regarding dust and heat stress, stakeholderbased decision support for land and water management.

The studies of the abovementioned work blocks are carried out along the entire Tarim River, including the Aksu River, in order to get an overview of the effects of different water availability schemes on anthropogenic activities and natural ecosystems (Fig. 2).

\section{Methods}

This paper is structured in the following way: climate change is the regional and trans-regional natural key indicator influencing all parts of the system in the Tarim River basin and thus stands at the beginning of the paper. The climate change section is followed by the hydrology section as it is directly influenced by climate change. Regional hydrology is extremely important. Changes in the hydrology affect ecosystems such as agricultural land, riparian forests, and urban vegetation. The authors here present different findings 

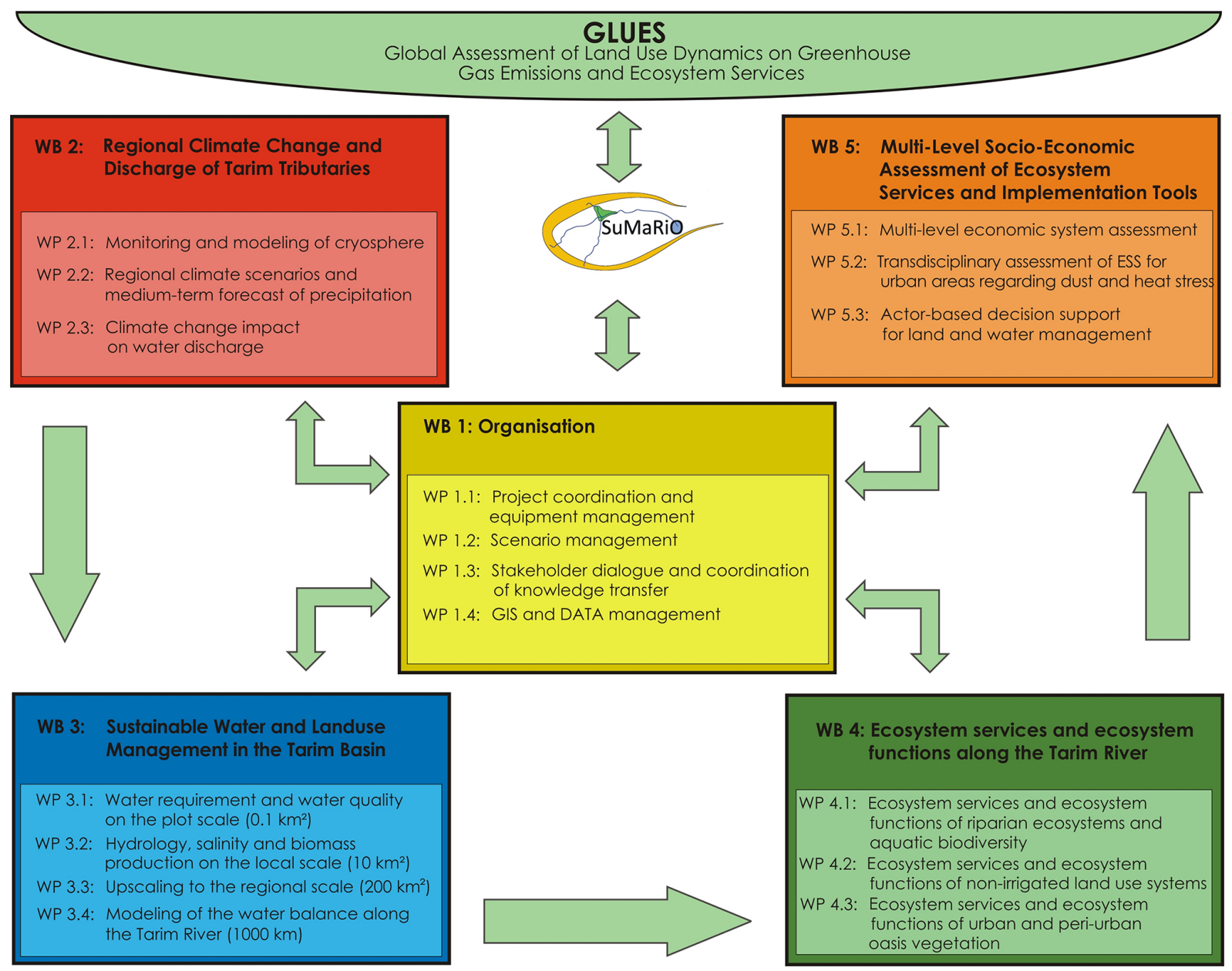

Figure 1. Structure of the SuMaRiO project (WB stands for work blocks and WP for work package).

to describe the current status of these ecosystems. At the end of the paper, the economic evaluation of non-use values involving citizens in the region and those distant and the involvement of regional stakeholders (transdisciplinary research) provide a holistic view of the problem of the Tarim River basin. An approach of supporting the problem solving of the region will be given in an outlook with a description of the project's overall result - a decision support tool.

\subsection{Climate change}

Climate trends were investigated in detail for the Aksu Catchment, which is the most important tributary of the Tarim River, constituting $80 \%$ of total water discharge into the main river. Climate data provided by the National Climate Centre of the China Meteorological Administration were used. In addition, the meteorological forcing data set from the WATCH project that is based on ERA-40 data (Weedon et al., 2011) and the APHRODITE data set (Yatagai et al., 2012) were used at a daily resolution. Trend analysis was performed using two methods: the linear regression and the
Mann-Kendall test. For the linear regression, the slope of the regression line and the standard error were estimated, and statistical significance of the trends was calculated. The trend analysis of temperature, precipitation, and river discharge was supplemented by a comprehensive correlation analysis investigating their interdependencies.

In addition, an analysis of historical climatic trends for the total Tarim River basin was done, and the results compared with those published in the literature. Due to the scarcity of observations we relied on girded data sets, namely CRU-TS3.21 (temperature and precipitation; Harris et al., 2014), GPCC-FD v6 (precipitation; Becker et al., 2013), and APHRODITE_MA V1101 (precipitation; Yatagai et al., 2012). Furthermore, we investigated a high-resolution gridded data set provided by the National Climate Centre, China Meteorological Administration (CMA, personal communication, 2012), which we believe has the most dense station network of all data sets, but only covers the Chinese part of the Tarim Basin. The trends were estimated using ordinary least squares regression. Trend significance was tested using the Mann-Kendall test. 


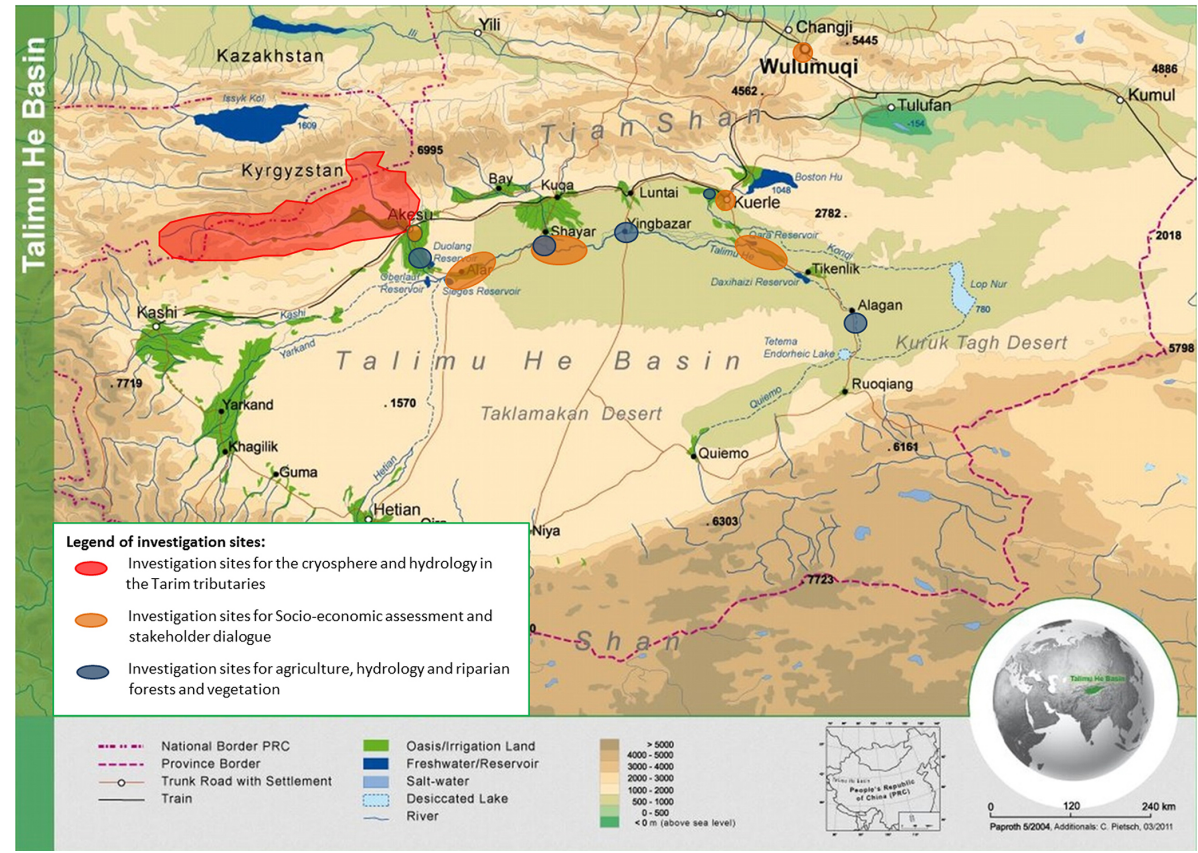

Figure 2. Map of the research area and investigation sites structured by the different scientific disciplines that contribute to SuMaRiO.

To investigate possible future changes, we employed two regional climate models, namely the statistical climate model STARS (Werner and Gerstengarbe, 1997; Orlowsky et al., 2008) and the dynamical climate model CCLM (COSMO Climate Local Model) (Steppeler, et al., 2003; Rockel et al., 2008). The CCLM and STARS simulations were successfully evaluated for the historical period. The simulations were compared to the results of 23 global climate models (GCMs) of the Coupled Model Intercomparison Project Phase 5 (CMIP5, http://cmip-pcmdi.llnl.gov/cmip5/). The regional climate models were successfully calibrated and evaluated for historical periods (see for example Wang et al., 2013). The RCP2.6, RCP4.5, and RCP8.5 emission scenarios were considered (see Meinshausen et al., 2011).

\subsection{Hydrology}

As precipitation is low, the Tarim Basin mainly depends on water from glacier and snowmelt. The cryosphere was investigated in the western Tian Shan in the greater catchment area of the Aksu River, a tributary of the Tarim River. The Tarim River starts at the confluence of the three rivers, the Hotan, Yarkant, and Aksu. With a discharge contribution of about $80 \%$, the Aksu River is the most important tributary of the Tarim River. The hydrological investigations focused on the two headwater catchments of the Aksu, the Sari-Djaz Catchment $\left(13000 \mathrm{~km}^{2}, 21 \%\right.$ glacier $)$ and the Kokshaal Catchment $\left(18400 \mathrm{~km}^{2}, 4 \%\right.$ glacier $)$, and a test site in Yingbazar at the mid-stream of the Tarim River. The runoff of the entirety of the Aksu and Tarim rivers is generated in the two headwater catchments from glacier and snowmelt as well as from rainfall. Downstream of those two headwater catchments, the Aksu and Tarim rivers behave as so-called "losing streams", i.e., they drain water into the groundwater layer, but do not receive any further runoff. Eighty percent of the annual discharge is formed during the summer season from April to September (Song et al., 2000).

First, trends in discharge during the high flow season (April-September) were analyzed, in order to demonstrate past discharge changes. Monthly streamflow data for the period 1957-2004 were available from Wang (2006). Second, the relationship between discharge and climate variability was investigated by analyzing correlations between summer discharge and summer precipitation and temperature. Mean monthly temperature and precipitation were retrieved from the GPCC v.6 (Schneider et al., 2011) and CRU 3.1 data sets (Mitchell and Jones, 2015), respectively. The analyses presented here are based on Krysanova et al. (2014) and Kundzewicz et al. (2014).

Second, a special analysis of high peaks in the river discharge time series and interrelations between discharge and climate parameters was performed for the Aksu gauges (Krysanova et al., 2014). It is known from the literature that the Aksu and Tarim rivers experience near-annually reoccurring flood events originating in the Aksu headwaters from the Merzbacher Lake due to glacier lake outburst floods (GLOFs). The implications of GLOFs for downstream areas and the related challenges for the hydrological modeling and the subsequent climate impact assessment were investigated in the Aksu basin using the Soil and Water Integrated Model (SWIM) model. The results were published in two 
research articles (Wortmann et al., 2013, Krysanova et al., 2014). Some partial results demonstrating the importance of GLOFs in the region are presented below.

Third, for an $85 \mathrm{~km}^{2}$ test site in the middle reaches (Yingbazar) the whole water cycle was modeled by the software MIKE SHE (DHI-WASY).

\subsection{Agricultural land}

Consuming by far the greatest amount of available fresh water resources, agriculture is the crucial factor with regard to sustainable water resource management in the Tarim River basin. To be able to develop recommendations for more sustainable water use in agriculture, the historical developments, current status, and improvement potential of irrigated agriculture were determined by applying a multi-disciplinary approach, including field experiments, a farm survey, crop modeling, and remote sensing.

Field experiments were established in order to determine the water-use efficiency of cotton cultivation under plastic mulched drip irrigation, which is the main irrigation type on soils of different degrees of salinization. Therefore, continuous measurements of certain parameters such as soil water content, water tension, and nutrient loads of leaching water by use of time domain reflectometer (TDR) tubes, tensiometers, and suction cups, respectively, were conducted during the cotton cultivation period. Measurements also included cotton yields. Afterwards, the Environmental Policy Integrated Climate (EPIC) model was used to model cotton production in relation to field management, soil types, and soil salinity. The results were upscaled through a SOTER (SOil TERrain) database of 50 soil profiles to a regional scale to generally simulate agricultural land use. These field experiments were established (1) in the upper reaches of the Tarim River basin (Aksu-Alar), (2) in the middle reaches, i.e., in Yingbazar, and (3) around Korla. At the three field plots, first the physical and chemical soil properties were investigated.

In addition to the simulated agricultural land use (cotton), current land use and land-use dynamics of the whole region were assessed with respect to the particular agricultural areas and current field management. Agricultural areas were assessed through examining remotely sensed time series of MODIS Enhanced Vegetation Index (EVI) Huete et al. (2002) data from the MOD13Q1 product (https://lpdaac.usgs.gov/products/modis_products_table/ $\bmod 13 q 1)$. The MODIS instrument provides data at a regional spatial scale $(250 \mathrm{~m})$ and at 16-day intervals. This coverage allows consistent observation of the phenological cycle within a year as well as land-use dynamics over the course of several years. To this end, a time series of 11 years (20012011) was compiled for the entire Tarim River basin, from which a set of 22 phenological descriptors was calculated for every year in the time series. These descriptors were used to characterize the different land-use systems and their dynamics. There are two main objectives: first, to produce a map of land-use systems for the most recent year in the time series, and second, to assess the increase in productive cropland during the entire time span. The latter problem was approached by applying suitable, knowledge-based thresholds to individual phenological parameters. These knowledge-based thresholds were calibrated by using small samples obtained in the field or from higher-resolution imagery.

Agricultural land use and water use is impacted by demographic development and socioeconomic change. In order to understand these impacts and to gain an overview of land use in the region, secondary production data were analyzed. These included data from the Statistical Yearbooks of Xinjiang (NBSCa, 1990-2012) and the Xinjiang Construction and Production Corps (NBSCb, 1990-2012), relevant policy documents (i.e., 5-year plans), and official ordinances related to land and water use. In addition, household interviews were conducted along the Aksu and Tarim rivers. Survey sites were selected purposefully according to their location in the direct vicinity to the river, while respondents within the village were selected randomly. In total 256 farmers were interviewed with respect to their detailed crop management of the 2011 growing season using a standardized quantitative questionnaire; only farm production data of the 212 cotton-producing farm households are presented in the current study.

\subsection{Riparian forests}

The major natural ecosystems along the Aksu and Tarim rivers are riparian ecosystems, which are comprised of riparian (Tugai) forests, shrub vegetation, reed beds, and other grasslands. Within the SuMaRiO cluster, the focus was set on the Tugai forests because they contain the most productive and species-rich natural ecosystems of the study region. The Tugai forests are dominated by Populus euphratica with Phragmites australis, Tamarix spp., Glycyrrhiza glabra, Alhagi sparsifolia, and Apocynum pictum as the main undergrowth species (Wang et al., 1996). The groundwater table, and thus finally the river runoff, which feeds the groundwater, plays a crucial role for the productivity, vitality, and actual evapotranspiration $\left(\mathrm{ET}_{\mathrm{a}}\right)$ of those forests (Wang et al., 1996; Thomas et al., 2006; Thevs et al., 2008a).

Within SuMaRiO, the productivity and vitality, both in relationship to the groundwater levels and the water supply of those forests, and the water consumption $\left(\mathrm{ET}_{\mathrm{a}}\right)$ were investigated in three plots in the middle reaches of the Tarim River, near the village of Yingbazar, in order to understand the effect of the groundwater table and runoff on productivity and vitality. The plots were located at distances of 7-11 km from each other and displayed groundwater tables between 2.0 and $12.0 \mathrm{~m}$. Each plot comprised a circular area with a radius of $50 \mathrm{~m}$ around a central tree.

On each plot, the position, tree height (with an ultrasonic hypsometer; Vertex IV, Haglöf, Långsele, Sweden) and stem diameter at breast height ( $\mathrm{dbh}$ ) were determined in all trees 
for all plots. In addition, the crown projection area was measured in 20 trees per plot using a plummet connected to a sighting tube (Grube, Bispingen, Germany). From those 20 trees, two increment cores per tree were removed in a horizontal $90^{\circ}$ angle at breast height with an increment borer $(\mathrm{Su}-$ unto, Vantaa, Finland). Tree-ring width was analyzed using a Lintab 6 tree-ring analysis system (Rinntech, Heidelberg, Germany) and TSAP-Win Professional 4.67c software (Rinntech). From the individual tree rings and increment cores, tree-wise and plot-wise average values were computed. Plotwise average ring widths were found to correlate with the river runoff of the preceding year after removing age trends of growth using standard methods (Rinn, 2003). Data on the annual runoff of the Tarim River at Yingbazar were provided by the Tarim Watershed Administration Bureau, Korla, China (Thevs et al., 2008b).

Additionally, the soil moisture and its connectivity were measured in a Tugai forest representative for the lower reaches of the Tarim near Arghan in order to get a better understanding of the water support for the natural vegetation. The soil moisture has been measured using Decagon 10HS sensors (Decagon, 2010) since November 2011 in hourly intervals. Pedotransfer-functions (third-degree regression) were used to describe the relationship between soil moisture content and $\mathrm{pF}$ values (Grashey-Jansen and Timpf, 2010; Grashey-Jansen et al., 2014). Applying this method, different sites with varying soil textures can be compared regarding the amount of plant-available water.

To estimate the connectivity between groundwater and soil moisture, cross correlations between the two time series were calculated. This indicates how long it took until the rising groundwater level has an effect on soil moisture in different layers.

Data on the vitality of the Tugai forests were collected in May 2013 at the same site in Arghan because here we found trees spanning the whole vitality range. At each soil moisture logger the surrounding Populus euphratica trees were surveyed using a classification scheme of six vitality classes ( $1=$ "very good condition" to $6=$ "dead"). The ranking was based on the visual impression of leaf density. Specimens of Populus euphratica that are in a good vitality condition will develop a higher density of leaves than those trees that suffer from, for example, water scarcity, and therefore are in poorer condition.

The field assessment of the Populus euphratica was complemented by a satellite image survey, in which changes of the tree crown areas between 2005 and 2011 were assessed. The two times were chosen in order to detect the response of Populus euphratica to restoration efforts in the lower reaches of the Tarim River whereby an object-based tree crown change detection method was applied to two veryhigh-resolution satellite images sets from 2005 (QuickBird QB) and 2011 (WorldView2 - WV2). A pixel-based minimum/maximum filter was applied to derived normalized difference vegetation index (NDVI) values in order to identify crown peaks and delineated the extracted peaks into individual tree crown objects using the region growing approach (Gärtner et al., 2014).

Finally, the water consumption of the natural ecosystem $\left(\mathrm{ET}_{\mathrm{a}}\right)$ was assessed. $\mathrm{ET}_{\mathrm{a}}$ of the natural ecosystems along the Aksu and Tarim rivers was mapped from MODIS satellite images for the years 2009, 2010, and 2011 (Thevs et al., 2013, 2014). The $\mathrm{ET}_{\mathrm{a}}$ was mapped after the S-SEBI approach as developed and described in detail by Roerink et al. (2000) and Sobrino et al. (2005, 2007), and as reviewed by Gowda et al. (2007, 2008). The following MODIS satellite data products were used in order to cover the whole Aksu-Tarim River basin: 8-day land surface temperature (MOD11A2), 16-day albedo (MCD43A3), and 16-day NDVI (MOD13A1). ET $_{\mathrm{a}}$ was mapped from April 1 to October 31 of each year because this time span corresponds with the growing season of the natural vegetation (Thevs et al., 2014).

Additionally, one climate station was operated in a Populus euphratica forest from 2009 in order to calculate $\mathrm{ET}_{\mathrm{a}}$ (Thevs et al., 2014). $\mathrm{ET}_{\mathrm{a}}$ was calculated with the Bowen ratio method (Malek and Bingham, 1993).

Afterwards, the $\mathrm{ET}_{\mathrm{a}}$ values for the following vegetation types were retrieved: wetlands, dense forests, forests, shrub, sparse woodland, and Apocynum pictum stands. Definitions are given in the caption of Table 5 in the results section. The $\mathrm{ET}_{\mathrm{a}}$ values of those different vegetation types were retrieved from MODIS pixels which represented the vegetation types. These MODIS pixels were located with the help of two QuickBird satellite images, from which forests and shrub were detected, and through field investigations from which the A. pictum stands were localized.

\subsection{Economic valuation of environmental change}

This interdisciplinary project supports oasis management by optimizing land and water management and thus contributes to the implementation of a sustainable strategy for the region. This includes different water distribution and land-use schemes along the Tarim River which have different effects on local natural ecosystems. Efficiency in the water management and land-use strategies are expected to lead to environmental improvements in the region. The question is whether the improvements are worth the costs of enhanced measures like more efficient irrigation technologies. While the costs of an environmental project can be determined rather straightforwardly on the basis of market prices like wages, capital costs, and material costs, an assessment of the benefits of improved environmental conditions is more complex. There are no market prices available for "goods" such as wildlife, landscape beauty, improved air quality. Therefore, particular valuation techniques have to be employed when determining the monetary value of a change in environmental quality.

In this study, direct valuation techniques were employed to assess the overall benefits of preserving natural vegetation in the Tarim River basin. Direct valuation techniques involve 
surveys, during which people are directly asked hypothetical questions concerning their willingness to pay for the environmental good in question. Since the restoration and maintenance of the natural vegetation along the Tarim River is likely to be especially beneficial for future generations which will have to deal with the adverse impacts of climate change, and also because of the (presumably great) existence value of the rare desert ecosystems in the region, direct valuation techniques turn out to be most suitable for a comprehensive assessment of the benefits of new water management and land-use strategies.

The contingent valuation method (CVM) is one of the most frequently applied direct valuation techniques (Mitchell and Carson, 1989). In CVM studies, an assessment of people's willingness to pay is based on personal interviews (faceto-face or by mail) with a representative sample of all households affected by a public project. The average willingness to pay of the households in that sample is then multiplied by the number of all households affected in order to obtain a monetary expression of the overall benefits obtained from the public project to society as a whole.

\subsection{Transdisciplinary research and stakeholder participation}

Transdisciplinary research (TR) has been implemented in SuMaRiO to support the generation of scientific output that can be used for supporting land and water management under climate change and uncertainty in the Tarim River basin. The focus was specifically on joint knowledge integration among scientists from multiple disciplines and stakeholders from various sectors (Siew and Döll, 2012). Knowledge of land and water management and ecosystem services were compiled and integrated into a TR process comprised of interviews and workshops. A combination of methods, namely actor modeling, Bayesian networks, and participatory scenario development, is applied for knowledge integration which includes the integration of results from SuMaRiO sub-projects.

Initially it was planned to conduct individual interviews with the representatives of relevant stakeholders, who were then to have participated in a series of five workshops (Siew et al., 2014). Their perceptions of problems should then have been brought together and integrated into a causal network (a perception graph). However, challenges in getting stakeholders involved in the process were encountered at the beginning. Therefore, the initial TR approach was altered by adding stakeholder analysis and intensifying the efforts of knowledge integration between German and Chinese scientists as well as among multiple disciplinary German scientists who are involved in SuMaRiO.

In November 2011 and November 2012, altogether 13 interviews were conducted with Chinese scientists from various disciplines. An overall perception graph of Chinese scientists was constructed. Additionally, an overall perception graph of German SuMaRiO researchers was generated. Both overall perception graphs were used as input for discussion in the first multilevel stakeholder dialogue (MLSD). Chinese scientists, who were and were not interviewed, and representatives from our key stakeholder, the Tarim River Basin Management Bureau (TRBMB), participated in the workshop. The overall perception graphs were updated after the first MLSD. In the second and third MLSDs, another key stakeholder, a representative of Xinjiang Water Resources Bureau (represented by the vice president), together with representatives from other governmental institutions, was also present. The updated overall perception graphs were used for further discussions in the second MLSD to develop shared problem perceptions. In the third MLSD, in which only Chinese stakeholders from government institutions (including water, agriculture, nature protection, and livestock husbandry) participated, the system description of the decision support tool (DST), storylines of two scenarios, and possible land and water management measures identified from the perspective of German scientists (developed in a workshop in Germany) were presented and discussed. In addition to using oral communication, questionnaires were used during workshops in Xinjiang to allow collecting specific information even from those who did not participate in the discussion.

By adapting our TR approach and methods for different methods of communication in local socio-cultural and institutional contexts, cross-sectoral and multidisciplinary communication and knowledge exchange was improved. Participants appreciated the format of the MLSD (including small group discussions of the World Café method), which enabled interactive discussion. The interactive MLSDs allowed the sharing of divergent perspectives on land and water management and ecosystem services, while it strengthened the mutual understanding among and was informative for stakeholders and scientists.

\section{Data management}

Due to the interdisciplinary and international layout of the SuMaRiO project, it was necessary to establish standardized mechanism for scientific data management. The implementation of approved standards for geodata, metadata, software, and graphical user interfaces was important to enable the interoperability and reusability of scientific spatial data. Our approach in this project was strongly influenced by international developments in geoinformatics in general and spatial data infrastructure (SDI) in particular. A large amount of SDI is currently being constructed on the national, European, and global level, and within scientific communities. All these efforts are based on the same set of standards and best practices, describing interfaces of web services, interoperability of data sources, etc., as there will be the standardization initiatives such as Open Geospatial Consortium (OGC), among others (OGC, 2014). 


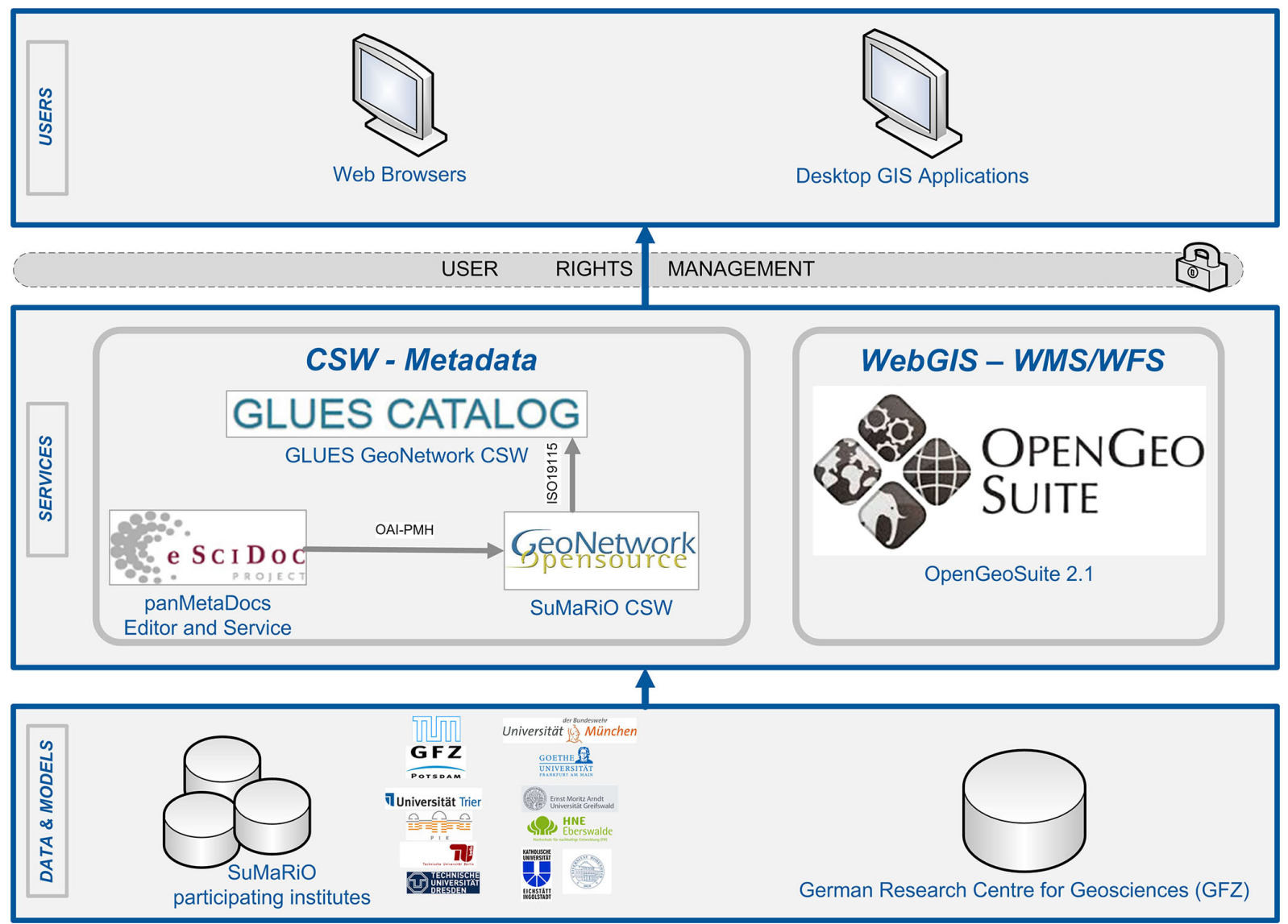

Figure 3. SuMaRiO workflow schema of a scientific spatial data infrastructure (SDI) node.

In order to achieve standardized data management, an umbrella project, GLUES (Global Assessment of Land Use Dynamics, Greenhouse Gas Emissions and Ecosystem Services), was established in the context of the Sustainable Land Management funding measure, funded by the German Federal Ministry of Education and Research (BMBF). The GLUES project supports several different regional projects of the LAMA (Nachhaltiges Landmanagement) initiative (GLUES, 2014). One of these regional projects is SuMaRiO. Within the framework of GLUES, SDI is being implemented to facilitate the publishing, sharing, and maintenance of globally and regionally distributed scientific data sets and model results. The GLUES SDI supports several OGC web services like the catalog service for the web (CSW) which enables it to harvest data from various regional projects. Each working group within SuMaRiO is dependent on results of other working groups. Due to the spatial distribution of participating institutions, the data distribution issue was solved by using the eSciDoc infrastructure at the German Research Centre for Geosciences (GFZ) (Ulbricht et al., 2014). The metadata-based data exchange platform PanMetaDocs was established and can be used in the collaboration of participants (Stender et al., 2014). PanMetaDocs supports an
Open Archives Initiative Protocol for Metadata Harvesting interface which enables an open source metadata portal like GeoNetwork to harvest the information (OAI-PMH, 2014). Subsequently this data will be harvested by the GLUES catalog as can be seen in Fig. 3. The figure shows the architecture of this newly established SuMaRiO infrastructure node with a superordinate network of the GLUES infrastructure (Schroeder and Wächter, 2012; Schroeder et al., 2013). Furthermore, a WebGIS solution with the web mapping service (WMS) and web feature service (WFS) was implemented. Both the metadata application and the WebGIS solution are available via the web portal of SuMaRiO (SuMaRiO, 2014).

The database of the project is used for the development of an indicator-based decision support tool (DST). This tool will enable stakeholders to see the consequences of their actions in terms of water and land management under particular climate and socioeconomic scenario assumptions. This can help balance economic benefits with ecosystem services. 


\section{Results and discussion}

\subsection{Climate change}

The observations show climate change in this region. There is general agreement that both temperature and precipitation have been increasing over the last few decades in the Aksu and Tarim basins (Tao et al., 2011). According to the analysis of Shangguan et al. (2009), which is based on data from 25 weather stations in the Tarim River basin, a warming of $0.77 \pm 0.16^{\circ} \mathrm{C}\left(0.019^{\circ} \mathrm{C} \mathrm{yr}^{-1}\right)$ and an increase in precipitation of $22.8 \pm 7.9 \%$ between 1960 and 2000 were found for the region.

Our results of observed trends in the Aksu basin are based on data from CMA and WATCH project for the period 19612001. The statistically significant positive trends in temperature were found for 30 out of 40 grid points in the lower Chinese part of the drainage area, and the average increase for 30 stations was $0.017^{\circ} \mathrm{C} \mathrm{yr}^{-1}$ (equivalent to $0.66 \pm 0.012^{\circ} \mathrm{C}$ in 40 years). All grid points without a significant trend are located in the western Chinese part of the basin. The temperature trends in the upper Kyrgyz part were statistically significant for all 10 grid points and higher than in the Chinese part: on average $0.026^{\circ} \mathrm{C} \mathrm{yr}^{-1}$ or $1.027 \pm 0.016^{\circ} \mathrm{C}$ in 40 years.

The positive, statistically significant trends in precipitation in the Aksu basin in 1961-2001 were found for 24 (30) out of 40 grid points in the Chinese part, where CMA data were used, for the Mann-Kendall (linear model) tests. The average increase for the 24 stations was $1.04 \mathrm{~mm} \mathrm{yr}^{-1}$, which is equivalent to $41.5 \pm 0.8 \mathrm{~mm}$ over 40 years. The trends are not statistically significant according to both tests for points located in the western part of the basin. All precipitation trends in the upper Kyrgyz part using APHRODITE and WATCH data were not statistically significant. The results of the detailed analysis of climatic trends in the Aksu basin are described in two research articles (Krysanova et al., 2014; Kundzewicz et al., 2014).

In addition, we used available climatic data sets to evaluate temperature and precipitation trends in the total Tarim drainage area. A significant increase of temperature and precipitation within the period 1962-2006 was found, which is in agreement with several other studies (see for example, Tao et al., 2011 and Chen et al., 2006). The results based on the CRU-TS3.21 and CMA data sets show a temperature increase of $0.3 \mathrm{~K}$ per decade. The results based on the CMA, GPCC-FD v6, and APHRODITE_MA V1101 data sets show an increase in precipitation of $6 \mathrm{~mm}$ per decade. All calculated trends were significant at a $5 \%$ significance level based on a Mann-Kendall test. Only CRU-TS3.21 data show an insignificant precipitation increase, possibly owing to the scarcity of the underlying station network in the Tarim Basin (Harris et al., 2014). Therefore, we can confirm, on the basis of multiple data sets, the observation of a shift towards a warmer and wetter climate of Shi et al. (2007).
Climate scenarios were evaluated for three future periods: 2011-2040 (STARS, CCLM, CMIP5), 2041-2070 (CCLM, CMIP5), and 2071-2100 (CCLM, CMIP5). According to climate projections, the increase in temperature and precipitation will continue past the aforementioned time period. Comparing the near-future period 2011-2040 with the baseline period 1981-2000, STARS projects a positive temperature change of 0.1 to $2.0 \mathrm{~K}$ and a precipitation change of -2 to $27 \mathrm{~mm}$ on the annual basis over all simulations and scenarios. CCLM shows a similar change for the near future with a temperature increase of $0.9 \mathrm{~K}$ for all scenarios and a precipitation increase between 11 and $35 \mathrm{~mm}$. The investigated GCMs show a similar change.

The precipitation increase is confined to late spring and early summer. We did not observe a statistical significant difference between the emission scenarios in the period 2011-2040. For the focus periods 2041-2070 and 20712100 the emission scenarios become distinguishable, with highest changes in precipitation projected for the high emission scenario RCP8.5. For the last future period 2071-2100, CCLM shows a temperature increase between 0.8 and $4.5 \mathrm{~K}$, and a precipitation increase of up to $38 \mathrm{~mm}$ compared to the baseline conditions. Furthermore, CCLM and the CMIP5 GCMs show a precipitation increase for the winter season in the middle and last projection periods. However, the overall change in all months is small (below $15 \mathrm{~mm}$ ) for all periods and scenarios. Also it can be noted that the range in the change signal of the CMIP5 models is considerably higher than others for all scenarios and is growing with time. Some GCMs show a decrease of up to $49 \mathrm{~mm}$ in annual precipitation.

\subsection{Hydrology}

The trend analyses showed significant increases in the summer discharge $(p<0.01)$ of the Aksu headwater catchments over the time span 1957-2004. Discharge increased by $152 \mathrm{~mm} \mathrm{yr}^{-1}$, or $23 \%$ relative to the mean flow over this period, in the Sari-Djaz Catchment, while discharge in the Kokshaal Catchment showed a lower increase in absolute terms of $88 \mathrm{~mm} \mathrm{yr}^{-1}$, but a stronger increase in relative terms of $35 \%$ (Fig. 4). However, the discharge did not increase in a uniform way over the whole period. The increase was particularly pronounced during the last decade. A period with relatively high discharge was also observed in the middle to late 1960s, while discharge values were rather low in the 1980s.

Correlation analyses of discharge and temperature/precipitation during the summer half year revealed a positive correlation of discharge with temperature for the highly glaciated Sari-Djaz Catchment (Spearman's $\rho=0.63, p<0.01$ ), while there was no significant correlation to precipitation. In contrast, in the Kokshaal Catchment, a weak but significant positive correlation to precipitation was found (Spearman's $\rho=0.50, p<0.01$ ), but the correlation to temperature was not significant. This is due to the 
different characteristics of the two headwater catchments: temperature variations play a large role for interannual discharge variations in the highly glacierized Sari-Djaz Catchment (Osomonov et al. 2013), and precipitation is more important in the Kokshaal Catchment, where snowmelt and rainfall have a stronger influence on the annual discharge amount. At other timescales, these relationships between climate and discharge parameters can be different. For example, at the daily timescale, discharge variations are strongly correlated to temperature variations in the Kokshaal Catchment also, resulting from increased snow and glacier melt on warmer days (Krysanova et al., 2014).

An analysis of high peaks in river discharge and the interrelationship of river discharge and climate parameters was performed for the headwater catchments of the Aksu, focusing on the Xiehela station on the Kumarik River (see details in Krysanova et al., 2014). The annually reoccurring GLOF of Merzbacher Lake, located in the Kyrgyz headwaters of the Aksu River, causes the discharge records to peak at the Xiehela station in late summer-autumn (end of AugustOctober). This unique hydrological event has had a significant impact on the discharge of the Aksu and Tarim rivers in the past (Glazirin, 2010; Wortmann et al., 2013), and has shown high volatility in terms of occurrence, peak discharge, and flood volumes. Although it is an erratic event, the occurrences show high dependence on local weather as well as the dynamics of the damming Inylchek glacier ( $\mathrm{Ng}$ et al., 2007). Wortmann et al. (2013) analyzed GLOFs by means of hydrological modeling with the SWIM model and using discharge records from the Chinese gauging station Xiehela, located some $200 \mathrm{~km}$ downstream of the lake. They were able to prove the occurrence of GLOFs in the discharge time series (see example in Fig. 4), and provided reliable flood volume estimations of between 100 and 250 million $\mathrm{m}^{3}$ per event, accounting for 3 to $6 \%$ of the total annual discharge at the Xiehela station.

The outburst events alter the annual discharge regime and pose a threat to infrastructure downstream as the floods' occurrence is shifting closer to the meltwater peak, i.e., leading to increased peak discharges in late summer. The construction of reservoirs immediately upstream of the Xiehela gauging station located some $200 \mathrm{~km}$ downstream of the lake has increased the importance of flood volume and peak discharge estimates and predictions. The Xiaoshixia Reservoir has been operational since 2012 with a maximum capacity of 69 million $\mathrm{m}^{3}$, and the second, much larger Dashixia reservoir is planned to be operational by 2019 with a maximum capacity of ca. 1274 million $\mathrm{m}^{3}$. Including these events in the planning of reservoir construction, in climate impact assessments, and management plans is a challenge for hydrological modelers and decision makers.

In the next step, possible impacts of climate change on water availability will be investigated using a scenario approach, i.e., climate scenarios will be applied as input to hydrological models. In such highly glacierized mountain catchments this

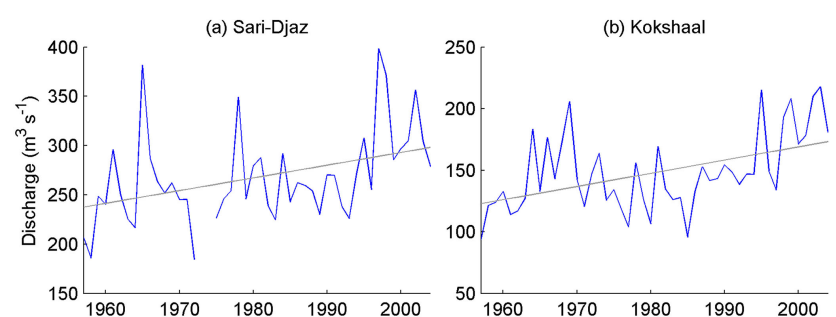

Figure 4. Average discharge for the summer season (April-Sept) for two headwater catchments of the Aksu River. (a) Sari-Djaz Catchment; (b) Kokshaal Catchment. Observations are shown in blue and the estimated trend line in gray.

approach has specific requirements. A robust parameterization is important considering that errors in simulated glacier melt may compensate for precipitation errors. This may be achieved with a multi-objective calibration. The model also needs to take account of dynamic changes in the glacier area either by incorporating externally generated future glacier area scenarios or by simulating glacier area changes. The ability to represent the discharge changes observed in the past can be an important control on applied hydrological models.

The increasing discharge from the Aksu headwaters results in more water resources available along the Aksu and Tarim rivers, attractive for the expansion of agricultural areas.

The modeling of the whole water cycle at Yingbazar showed that in the year 2012, the natural annual summer flood constituted $114 \mathrm{~mm}(98 \%)$ of the groundwater recharge. The groundwater recharge is that amount of water which is stored in the aquifer after evapotranspiration and infiltration losses. In the meantime, dikes have been built along nearly the whole upper and middle reaches, except for Yingbazar. However, there are locks at major river branches so that the river branches may receive water from the Tarim River. If dams were built in Yingbazar, too, and the floods only entered through such a lock, the groundwater recharge by the flood would drop to $41 \mathrm{~mm} \mathrm{yr}^{-1}$ (62\%) (Fig. 5) (Keilholz, 2014).

\subsection{Agricultural land}

Over the last 2 decades, utilized land area has expanded greatly along the Tarim River. The total agricultural land-use area more than doubled from 1989 to 2011. In recent years, cotton and tree fruit have become the main agricultural commodities (Fig. 6).

The agricultural land-use trends observed in the official statistics are confirmed by the MODIS data analysis, with the largest increase of cropland occurring between 2004 and 2008. The most rapid changes were observed in Aksu and Korla, where there was an expansion of cotton production in the state-operated farms of the Xinjiang Construction and Production Corps at the fringes of the large oases located in these districts. In Aksu, it was estimated that the area of 

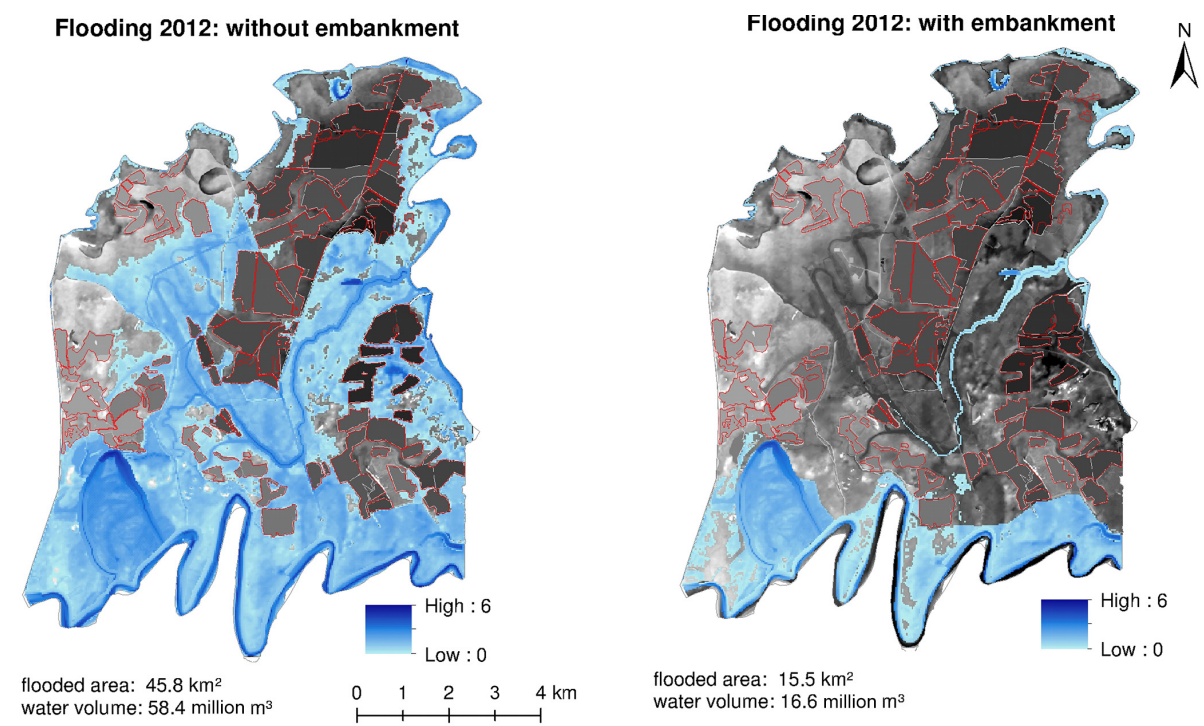

Figure 5. Different modeled flooding scenarios without (right panel) and with embankment (left panel) along the Tarim River using the discharge volume of the flood of 2012.

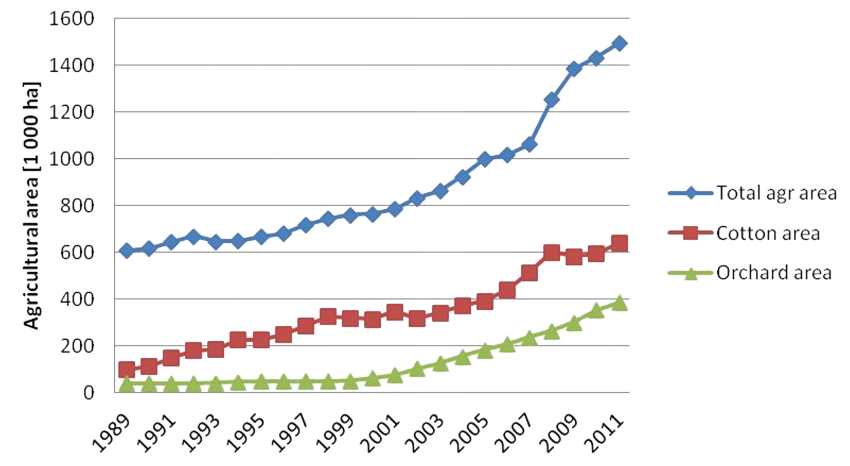

Figure 6. Development of total agricultural land-use area and cotton and orchard area in the Tarim Region over the last 2 decades (calculated from NBSCa, 1990-2012, and NBSCb, 1990-2012).

productive cropland increased by more than $300 \mathrm{~km}^{2}$ every 4 years.

The MODIS time series showed that the area of productive cropland increased from about $18000 \mathrm{~km}^{2}$ in 2001 to about $25000 \mathrm{~km}^{2}$ in 2011 for the Tarim River basin, including the Aksu River Basin. In 2011, large-scale highly productive cotton monoculture, less-productive cotton systems, and small-scale Uighur cropping systems and marginal agriculture mixed with semi-natural vegetation covered 11000 , 4000 , and $10000 \mathrm{~km}^{2}$, respectively. The existence of less productive and marginal mixed crop land indicates that actual crop water requirements can no longer be fully satisfied for the vast, expanding crop land. The traditional Uighur land-use system is characterized by fields in rather small parcels of land with permanent tree cultivation (e.g., walnut or fruit trees) in combination with a rotation of crops, most frequently maize and winter wheat, planted under the trees. Cotton, on the other hand, is typically grown in intensive monocultures since it requires a fair amount of light intensity to grow. Figure 7 shows the distribution of those landuse systems for the Aksu River Basin and the Tarim upper reaches as an example.

Apart from the steady increase in population and the related agricultural labor force, the very good producer price developments for cotton and tree fruit, in particular, has obviously driven the reclamation of crop land (Fig. 8).

The insufficient control over land reclamation has supported agricultural land expansion. This has resulted in an increased water demand by the agricultural sector. Local government actors have realized the urgency of the problem, and are aiming for the stabilization of agricultural land, while shifting the agricultural labor force into other industries (Feike et al., 2014). Increased investment into agricultural extension services seems to be a viable option in order to improve farmers' management and water-use efficiency and thus reduce agricultural water consumption; however, solely increasing the price of water for farmers might have no positive effect with regard to a reduction of water consumption (Mamitimin et al., 2014).

The massive increase in irrigation agriculture in the Tarim River basin has caused reduced river runoff and increased evaporation from agricultural land (Yao et al., 2013). This has led to an increase in salinity levels in soils and upper aquifers (Han et al., 2011), posing a question on the impact of increasing salinity on crop yields. Therefore, field conditions were investigated.

At two experimental sites along the river, chemical and physical soil properties, soil water content, soil suction and matric suction, cotton yield, and water-use efficiency under 

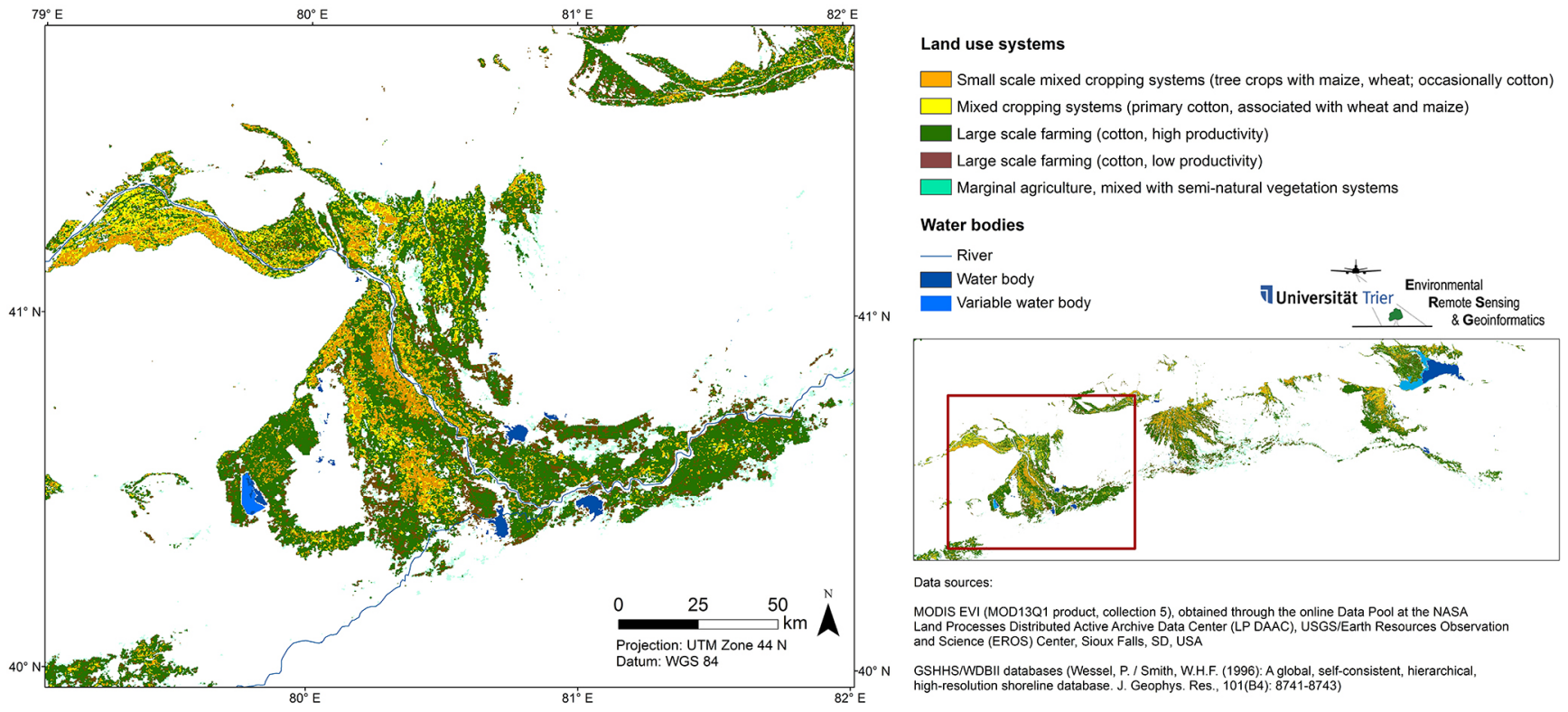

Figure 7. A map of land-use systems for the Aksu oasis in 2011.

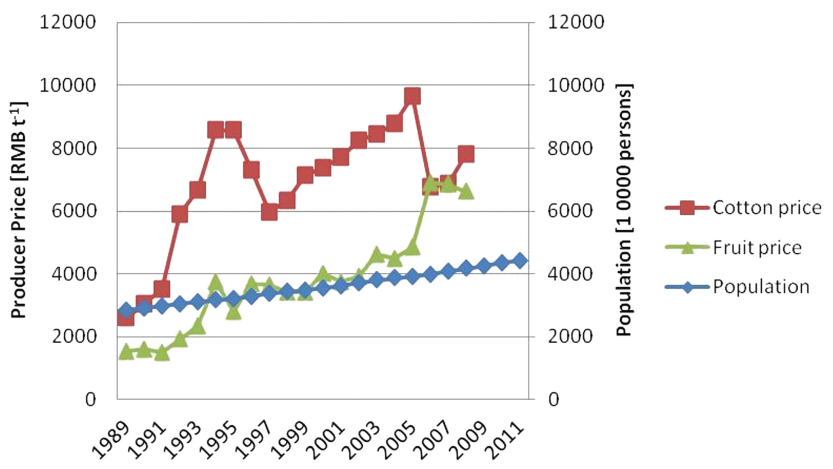

Figure 8. Development of producer prices of the major agricultural commodities cotton and tree fruit, as well as population development in the Tarim Region in the last 2 decades (calculated from NBSCa, 1990-2012 and NBSCb, 1990-2012; FAOSTAT, 2012).

plastic mulched drip irrigation in different saline soils were measured in the cotton growth season to study the influence of soil salinity on cotton yields. At the two investigation sites, three soils with different degrees of soil salinity were chosen: low soil salinity in Korla $\left(17-25 \mathrm{mS} \mathrm{cm}^{-1}\right)$, medium soil salinity in Aksu $\left(29-50 \mathrm{mS} \mathrm{cm}^{-1}\right)$, and high soil salinity in Aksu (52-62 $\mathrm{mS} \mathrm{cm}^{-1}$ ) over a soil profile of $100 \mathrm{~cm}$. The low saline soil in Korla had the highest cotton yield $\left(6.6 \mathrm{tha}^{-1}\right)$, the highest irrigation water-use efficiency (IWUE; $0.012 \mathrm{tha}^{-1} \mathrm{~mm}^{-1}$ ), and the highest water-use efficiency (WUE; $0.001 \mathrm{tha}^{-1} \mathrm{~mm}^{-1}$ ). High water content below the $30 \mathrm{~cm}$ soil profile in high saline soil increased the risk of salinity and led to lower cotton yield $\left(2.4 \mathrm{tha}^{-1}\right)$. The salinity stress for cotton was prevented by low soil matric potential $(>30 \mathrm{kPa})$ during the vegetation period in Korla and thus produced the highest yield. Compared to high saline soils in Aksu, the low salinity soil in Korla saved $117 \mathrm{~mm}$ of irrigation and $100 \mathrm{~mm}$ of total water to reach $1 \mathrm{tha}^{-1}$ cotton yield and increased 0.005 and $0.007 \mathrm{tha}^{-1} \mathrm{~mm}^{-1}$ for WUE (water-use efficiency) and IWUE (irrigation water-use efficiency), respectively. The collected soil salinity data were basis for the modeling of cotton yields on different soil types in Aksu-Alar region.

The EPIC model simulation under the current conditions of field management and irrigation scheme showed best estimated cotton yield on Calcic Gleysols (GLcc) with $7.78 \mathrm{tha}^{-1}$. Gleyic Phaeozems (PHca), Gleyic Fluvisols (FLgl), Gleyic Solonchaks (SCgl) and Gypsic Solonchaks (SCgy) (soils classified in the field after IUSS working Group WRB, 2006) resulted in high estimated cotton yield. The lowest estimated cotton yield was on Haplic Arenosols (ARha) and Puffic Solonchaks (SCpu) with 3.11 and $3.74 \mathrm{tha}^{-1}$, respectively (Fig. 9).

Based on the findings, for sustainable management it is recommended to cultivate cotton under low salinity. A comparison shows that, on fields with low soil salinity, $4 \mathrm{tha}^{-1}$ more yield can be harvested and $1000 \mathrm{~m}^{3} \mathrm{ha}^{-1}$ water can be saved than on fields with high soil salinity.

To minimize salinity-induced yield losses, farmers in the region try to flush accumulated salts out of the rooting zone by flooding their fields twice a year (Shen and Lein, 2010). As reduced water availability hinders effective control of salinity of all crop land, it is important to increase the availability of water for flushing by reducing overall agricultural water use. Therefore, farmers' water consumption and the agronomic and economic performance of cotton production 
Table 1. Average water consumption, yield level, and farmers' perceived salinity of cotton production of drip and flood irrigating farm households along the Tarim River.

\begin{tabular}{|c|c|c|c|c|c|c|c|c|}
\hline \multirow{2}{*}{$\begin{array}{l}\text { Irrigation } \\
\text { method }\end{array}$} & \multirow{2}{*}{$\begin{array}{c}\text { No. } \\
\text { of farms }\end{array}$} & \multicolumn{3}{|c|}{ Water consumption } & \multirow{2}{*}{$\begin{array}{c}\text { Yield } \\
{\left[\mathrm{kg} \mathrm{ha}^{-1}\right]}\end{array}$} & \multicolumn{3}{|c|}{ Salinity problems } \\
\hline & & $\begin{array}{c}\text { Irrigation } \\
{\left[\mathrm{m}^{3} \mathrm{ha}^{-1}\right]}\end{array}$ & $\begin{array}{c}\text { Flushing } \\
{\left[\mathrm{m}^{3} \mathrm{ha}^{-1}\right]}\end{array}$ & $\begin{array}{c}\text { Total } \\
{\left[\mathrm{m}^{3} \mathrm{ha}^{-1}\right]}\end{array}$ & & Yes & $\begin{array}{c}\text { Increasing } \\
{[\% \text { of far } 1}\end{array}$ & $\begin{array}{l}\text { Decreasing } \\
\text { ers] }\end{array}$ \\
\hline Drip & 115 & 4164.3 & 2791.5 & 6955.8 & 5533.9 & 83.5 & 65.2 & 15.7 \\
\hline Flood & 113 & 5391.9 & 3036.4 & 8428.2 & 3906.1 & 77.0 & 48.7 & 26.5 \\
\hline Total & 228 & 4772.7 & 2912.9 & 7685.6 & 4727.1 & 80.3 & 57.0 & 21.1 \\
\hline
\end{tabular}

Table 2. Economic key figures of cotton production of drip and flood irrigating farm households along the Tarim River.

\begin{tabular}{lccccc}
\hline $\begin{array}{l}\text { Irrigation } \\
\text { method }\end{array}$ & $\begin{array}{c}\text { Number of } \\
\text { farms }\end{array}$ & $\begin{array}{c}\text { Total } \\
\text { variable } \\
\text { cost } \\
\text { USD ha }^{-1} \text { ] }\end{array}$ & $\begin{array}{c}\text { Irrigation } \\
\text { variable } \\
\text { cost } \\
\text { [USD ha }^{-1} \text { ] }\end{array}$ & $\begin{array}{c}\text { Revenue } \\
{\left[\mathrm{USD} \mathrm{ha}^{-1} \text { ] }\right.}\end{array}$ & $\begin{array}{c}\text { Gross } \\
\text { margin } \\
{\left[\mathrm{USD} \mathrm{ha}^{-1} \text { ] }\right.}\end{array}$ \\
\hline $\begin{array}{l}\text { Drip irrigation } \\
\text { Flood irrigation }\end{array}$ & 115 & 5097.5 & 849.7 & 7182.4 & 2084.9 \\
\hline Total & 113 & 3907.1 & 440.1 & 5107.2 & 1200.1 \\
\hline
\end{tabular}

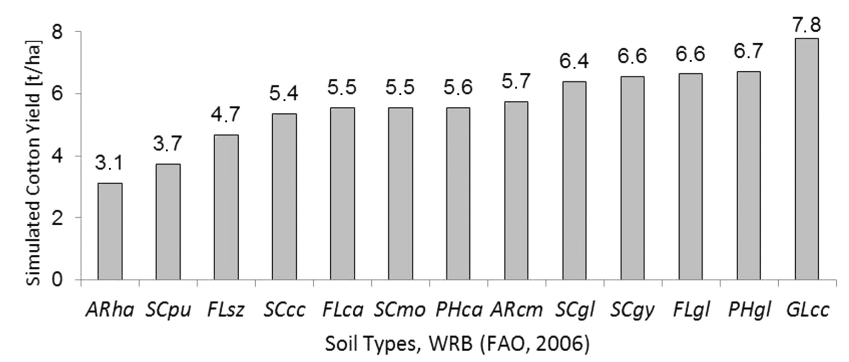

Figure 9. Average simulated cotton yield of each soil type in AksuAlar $\left[{ }^{*} \mathrm{ha}^{-1}\right]$.

under the two prevailing irrigation techniques - drip and flood irrigation - were investigated by field survey.

Huge differences were observed between farms using drip irrigation versus flood irrigation. Table 1 displays the total water consumption under drip irrigation, around $1500 \mathrm{~m}^{3} \mathrm{ha}^{-1}$, is less compared to flood irrigation.

At the same time the average yield obtained under drip irrigation was more than $1500 \mathrm{~kg} \mathrm{ha}^{-1}$ higher than under flood irrigation. The observed yield levels under drip irrigation are in line with results from Wang et al. (2012), who reported yield levels of 5000 to $6400 \mathrm{~kg} \mathrm{ha}^{-1}$ from field experiments in Xinjiang.
Around $80 \%$ of cotton farmers reported that soil salinization problems occur in their fields. Salinization problems have increased in recent years for most farmers, especially under drip irrigation. This indicates that the reduced irrigation amount under drip irrigation constitutes a challenge to soil salinity management. Looking at the economic performance of cotton production (Table 2) drip irrigation entails nearly twice the variable cost for irrigation compared to flood irrigation. However, the higher yield level under drip irrigation led to an average gross margin, which was 800 USD ha $^{-1}$ higher compared to flood irrigation. Fixed investment costs for the drip irrigation system were estimated between 180 and $350 \mathrm{USD} \mathrm{ha}^{-1} \mathrm{yr}^{-1}$ by Wang et al. (2012). Thus, for the sampled farm households, drip irrigation seems a viable option for cotton irrigation along the Tarim River, performing better in agronomic and economic terms over flood irrigation. However, flood irrigation has lower capital costs and thus requires less capital for the farmers.

To reduce water-shortage-induced ecosystem degradation and agricultural productivity losses, it is essential to reduce agricultural water consumption. Promoting drip irrigation and restricting agricultural land use can help save water (which thus becomes available for natural ecosystems) and is an effective salinity management technique for the remaining crop land. The results of the farm survey show that the higher yields generated by drip irrigation would allow for higher productivity and farm incomes even under reduced agricultural production area. 
Table 3. Stand structure and tree morphology of the three Populus euphratica study plots near Yingbazar with short (GD1; 2.0 m), intermediate $(\mathrm{GD} 2 ; 7.5 \mathrm{~m})$ or long distance $(\mathrm{GD} 3 ; 12.0 \mathrm{~m})$ to the groundwater (mean \pm standard deviation, if applicable). Different lower-case letters indicate statistically significant differences among the plots (Kruskal-Wallis $H$ test, followed by multiple pairwise Mann-Whitney $U$ tests).

\begin{tabular}{|c|c|c|c|}
\hline Plot & GD1 & GD2 & GD3 \\
\hline Number of trees per plot & 367 & 297 & 53 \\
\hline Stand density (trees ha ${ }^{-1}$ ) & 467 & 378 & 67 \\
\hline Basal area $\left(\mathrm{m}^{2} \mathrm{ha}^{-1}\right)$ & 18.7 & 15.7 & 13.3 \\
\hline Tree cover (\%) & 75 & 31 & 6 \\
\hline Maximum tree age (yr) & 68 & 141 & 314 \\
\hline Tree height $(\mathrm{m})$ & $10.6 \pm 5.3 a$ & $7.6 \pm 1.8 b$ & $5.2 \pm 2.2 c$ \\
\hline Diameter at breast height $(\mathrm{dbh})(\mathrm{m})$ & $0.20 \pm 0.10 b$ & $0.21 \pm 0.08 b$ & $0.44 \pm 0.24 a$ \\
\hline Height: dbh & $55.4 \pm 15.7 a$ & $39.2 \pm 12.3 b$ & $15.5 \pm 9.3 c$ \\
\hline
\end{tabular}

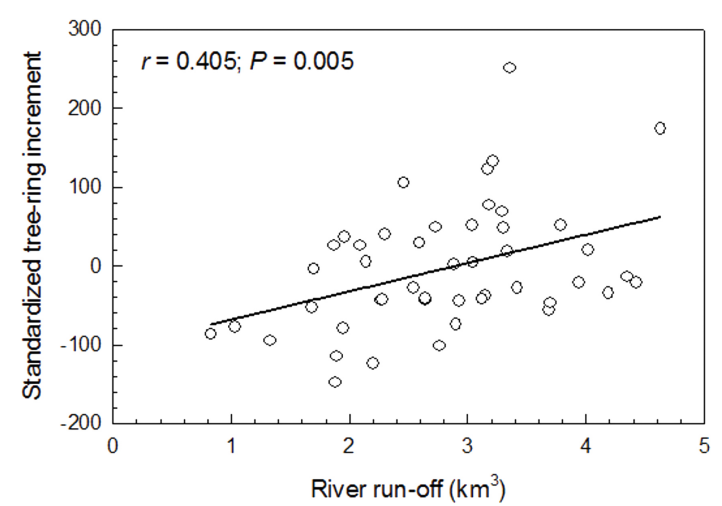

Figure 10. Standardized annual stem diameter increment of Populus euphratica trees growing on study plot GD1 at short distance ( $2.0 \mathrm{~m}$ on average) to the water table plotted against Tarim River's runoff of the preceding year at Yingbazar during the time period 1957-2005. $n=47$. $r$, Pearson correlation coefficient.

\subsection{Riparian forests}

In the Tugai forests in Yingbazar, tree age was lowest at the shortest groundwater distance and highest in the plot with the longest distance to the water level (Table 3). The number of trees, the stand density, basal area, tree cover, and tree height all decreased with increasing distance to the water table. These differences in the stand structure were also reflected in the stem morphology: dbh was largest and the height: dbh ratio was lowest in the plot with the longest distance to the groundwater.

Minimum, average, and maximum tree-ring width decreased with increasing distance to the water table (Table 4). In the plot closest to the groundwater (but not in the two plots further from the groundwater), the standardized stem diameter increment correlated significantly with the Tarim River runoff of the preceding year for the time period of 1957 to 2005, for those years with runoff data available (Fig. 10).

The connection between runoff of the Tarim River and the soil moisture was studied at a research site in the lower reaches. At this site, the soil moisture conditions are suitable for the existing vegetation. Within all soil layers deeper than $50 \mathrm{~cm}$ from the surface, the soil water content is within the plant available range during the whole measuring period (see Fig. 11). Seasonal trends are not very strong and probably overlaid by effects of artificial water releases. The effect of those water releases can best be seen in the time period of September 2013 to January 2014. Immediately after the rise of the groundwater level - which is induced by increased river discharge - the mean $\mathrm{pF}$ values react. It can be seen from Fig. 11 that deeper levels show an earlier increase in soil water content that shallower ones.

This effect is exemplarily shown in Fig. 12. Here the cross correlation functions (ccf) for sensor $1(-60 \mathrm{~cm})$ and 3 $(-150 \mathrm{~cm})$ and the groundwater level are shown for the time frame September 2013 to January 2014. The red dots mark the time lag with the highest correlation coefficient.

For the sensor at $150 \mathrm{~cm}$ depth, the time lag is equal to 0 (1 time step is equal to $2 \mathrm{~h}$ ). Thus, the soil water content shows a reaction to rising groundwater within the measurement period of $2 \mathrm{~h}$. So, it can be stated that there is high connectivity between groundwater and soil moisture due to (1) relative short distance between groundwater table and soil moisture sensor and (2) high water conductivity of the soil. The time until the rising groundwater is notable in shallower soil layers is much greater. The sensor at $60 \mathrm{~cm}$ depth has a time lag of $41(82 \mathrm{~h})$, which means that the soil moisture content in this layer increased 3.5 days after the groundwater started rising.

Qualitative results show that the surface-groundwater distance is not the only factor determining vegetation condition within the examined corridor. Soil conditions, especially fine-sediment layers, play a crucial role. The soil moisture data indicate that water availability within the measurement period is sufficient to maintain the existing vegetation, disregarding other factors. However, the decisive morphodynamic component of the Tugai ecosystem is missing. A comparison of remote sensing data from 1964 and 2014 has shown that the river channel has not changed within that period. River dynamics are important for the establishment of juvenile trees and thus the formation of new forest stands, which 


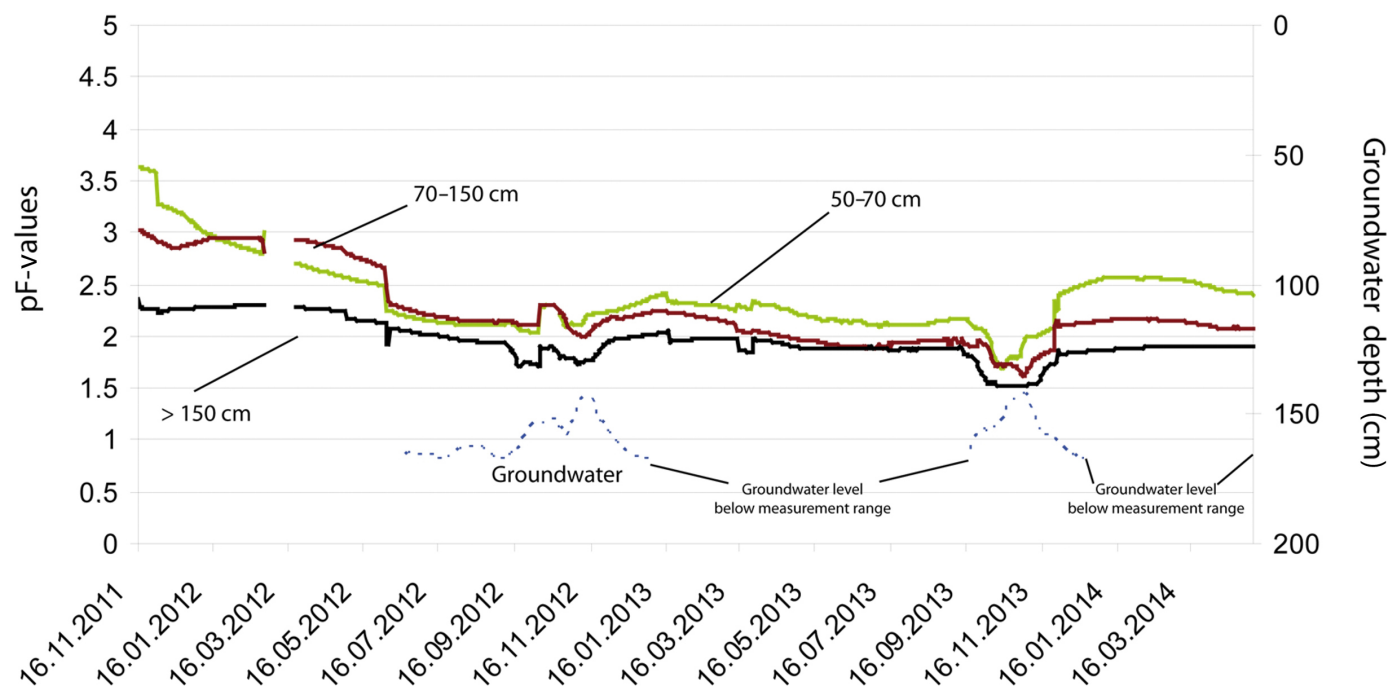

Figure 11. Mean $\mathrm{pF}$ values of all soil moisture stations for different soil layers.

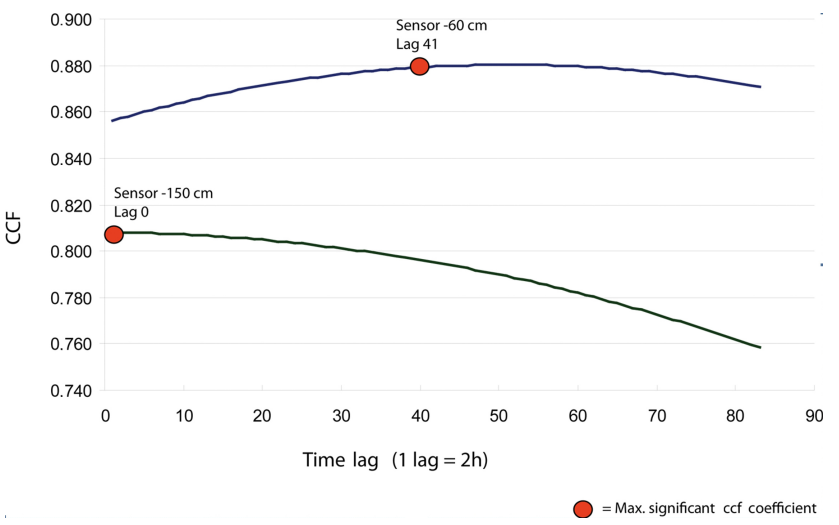

Figure 12. Cross-correlation function of two sensors of logger no. 13 and the groundwater level for September 2013 to January 2014.

is a major factor influencing the vitality - in the sense of rejuvenation - of the forest stands (see Thevs et al., 2008b).

In the same area in the lower reaches, the analysis of the very-high-resolution QuickBird and WorldView satellite images showed a loss of 180 Populus euphratica trees and a gain of 25 new trees between observations in 2005 and 2011. This confirms that the altered river dynamics, as found along the lower reaches, result in the absence of young trees there. However, positive tree crown growth, with an average crown diameter increase of $1.14 \mathrm{~m}$ between 2005 and 2011, was observed (Gärtner et al., 2014).

The $\mathrm{ET}_{\mathrm{a}}$ of the natural vegetation is shown in Table 5. In all vegetation types, except for sparse woodland, the $\mathrm{ET}_{\mathrm{a}}$ of the growing seasons increases from 2009 over 2010 to 2011. This trend is most pronounced in dense forests, with an $\mathrm{ET}_{\mathrm{a}}$ of 735, 777, and $1068 \mathrm{~mm}$ during the growing seasons of 2009, 2010, and 2011, respectively. The $\mathrm{ET}_{\mathrm{a}}$ calculated from the climate data (Table 5) follows this trend, too. The sum
Table 4. Minimum, average and maximum tree-ring widths of Populus euphratica and time period covered by tree-ring analyses in stands with short (GD1), intermediate (GD2), and long distance (GD3) to the groundwater (mean values of all available years with standard deviations). Different lower-case letters indicate statistically significant differences among the stands (Kruskal-Wallis $H$ test, followed by multiple pairwise Mann-Whitney $U$ tests).

\begin{tabular}{lcrc}
\hline Plot & $\begin{array}{c}\text { Minimum } \\
\text { width } \\
(\mu \mathrm{m})\end{array}$ & $\begin{array}{r}\text { Mean } \\
\text { width } \\
(\mu \mathrm{m})\end{array}$ & $\begin{array}{c}\text { Maximum } \\
\text { width } \\
(\mu \mathrm{m})\end{array}$ \\
\hline GD1 (1946-2011) & 100 & $1794 \pm 452 a$ & 8865 \\
GD2 (1862-2011) & 50 & $1085 \pm 277 b$ & 8515 \\
GD3 (1683-2011) & 30 & $526 \pm 207 c$ & 2880 \\
\hline
\end{tabular}

of the daily $\mathrm{ET}_{\mathrm{a}}$ values over the 2009 growing season measured at the climate station Iminqak nearly equals the $\mathrm{ET}_{\mathrm{a}}$ detected from the MODIS satellite images (Table 6). In 2011, the MODIS $\mathrm{ET}_{\mathrm{a}}$ is $10.8 \%$ higher than the $\mathrm{ET}_{\mathrm{a}}$ measured at the climate station.

The trend of the $\mathrm{ET}_{\mathrm{a}}$ can be explained as follows: 2009 was an extremely dry year with no summer flood. 2010 was dry, too, until the summer flood started. The summer flood of 2010 was extremely high so that large areas of the natural vegetation, especially dense forests, were flooded and stayed partly flooded until early summer 2011. Therefore, in the second half of 2010 more water was available to be consumed by natural vegetation. In 2011, there was abundant water available throughout the whole growing season. In addition, during spring and early summer, water from flooded areas evaporated.

During the late 1970s and early 1980s, the local government of Aksu realized the importance and urgency of urban greening for sustainable urban development, and since then 
Table 5. $\mathrm{ET}_{\mathrm{a}}[\mathrm{mm}]$ of the natural vegetation along the Aksu and Tarim rivers during the vegetation seasons 2009, 2010, and 2011. $N-$ number of MODIS pixels, SD - standard deviation. Natural vegetation: dense forest - total coverage of $>50 \%$, forest - total coverage of $>25 \%$ and $<=25 \%$ with tree coverage higher than shrub coverage, shrub - total coverage of $>25 \%$ and $<=25 \%$ with tree coverage lower than shrub coverage, sparse woodland - total coverage of $>10 \%$ and $<=25 \%$. A. pictum stands cover more than $50 \%$ of the MODIS pixels (Thevs et al., 2013).

\begin{tabular}{lccccccccc}
\hline Vegetation & $N$ & $\begin{array}{c}\mathrm{ET}_{\mathrm{a}} \\
\text { mean } \\
{[\mathrm{mm}]}\end{array}$ & $\mathrm{SD}$ & $N$ & $\begin{array}{c}\mathrm{ET}_{\mathrm{a}} \\
\text { mean } \\
{[\mathrm{mm}]}\end{array}$ & $\mathrm{SD}$ & $N$ & $\begin{array}{c}\mathrm{ET}_{\mathrm{a}} \\
\text { mean }\end{array}$ & SD \\
{$[\mathrm{mm}]$} & \\
\hline Wetlands & 10 & 1687 & 373 & 10 & 1660 & 298 & 10 & 1790 & 248 \\
Dense forest & 41 & 735 & 135 & 41 & 777 & 149 & 66 & 1068 & 210 \\
Forest & 90 & 554 & 221 & 90 & 612 & 247 & 129 & 725 & 296 \\
Shrub & 24 & 292 & 221 & 24 & 295 & 218 & 38 & 346 & 190 \\
Sparse woodland & 33 & 230 & 225 & 33 & 277 & 238 & 59 & 224 & 272 \\
A. pictum & 2 & 31 & 65 & 2 & 86 & 22 & 5 & 142 & 80 \\
\hline
\end{tabular}

Table 6. Sum of $\mathrm{ET}_{\mathrm{a}}$ during the growing seasons (2009 to 2011) measured with the climate station Iminqak and detected through remote sensing (Thevs et al., 2014).

\begin{tabular}{cccr}
\hline Year & \multicolumn{3}{c}{ Sum of $\mathrm{ET}_{\mathrm{a}}$ during growing season $[\mathrm{mm}]$} \\
\cline { 2 - 4 } & $\begin{array}{c}\text { Climate } \\
\text { station }\end{array}$ & $\begin{array}{c}\text { Remote } \\
\text { sensing }\end{array}$ & $\begin{array}{r}\text { Deviation } \\
{[\%]}\end{array}$ \\
\hline 2009 & 612 & 611 & 0.2 \\
2010 & & 794 & 10.8 \\
2011 & 836 & 929 & \\
\hline
\end{tabular}

has taken great efforts to increase forest coverage. As a result, urban green coverage within the built-up area climbed to 1350 ha in 2012 , now occupying more than one third of the urban built-up area. Meanwhile, urban green coverage as percentage of built-up area (green coverage ratio, GCR) also keeps increasing. In 1985, GCR was less than $15 \%$, and in 2012 , it reached about $36 \%$. This indicates the continuous attention and efforts of the relevant urban authorities regarding urban greening.

By end of 2015, the total amount of water consumption for urban greening is estimated to reach about 21.3 million $\mathrm{m}^{3}$ per year (Municipal Government of Aksu, 2007). For the irrigation of urban green space, water saving irrigation methods like sprinkler irrigation and drip irrigation will be predominantly used, and the irrigation quota will be controlled to remain below $6750 \mathrm{~m}^{3} \mathrm{ha}^{-1} \mathrm{yr}^{-1}$ (Municipal Government of Aksu, 2007).

\subsection{Economic valuation of environmental change - willingness to pay}

The research done in the SuMaRiO sub-projects as described in the previous sections illustrated the impact of increasing water shortages along the Tarim River on the vegetation and the living conditions in the lower reaches of the Tarim. The deterioration of trees also affects the ecosystem services that are provided by Populus euphratica trees, such as soil stabilization, weakening sandstorms, and filtering dust from the air during sandstorms. If current development continues, future generations will be faced with rather harsh living conditions in those regions.

If the Chinese government decides to intervene in the agricultural sector in the middle reaches of the Tarim in order to make land and water use there more sustainable, it will have to incur considerable costs to set the right incentives for such development. Government funds will be needed for paying subsidies or premiums to farmers for the implementation of more efficient irrigation systems and for payments to farmers to compensate them for forgone profits as a consequence of reduced use of fertilizers and pesticides as examples. In order to realize a net social benefit with its policy actions, governments have to make sure that the social costs of such a project do not exceed the social benefits. While the project costs can be calculated rather straightforwardly on the basis of market prices (labor costs, capital costs, cost of materials, etc.), this is not possible for the social benefits obtained from such a project since there exist no market prices for the terrestrial and aquatic ecosystems of the Tarim River and the ecosystem services they provide.

The welfare economic valuation method tests, improves, and applies a specific valuation technique, the CVM as described in Sect. 2.6, for the assessment of the social benefits that would be obtained from a practical implementation of the policy measures suggested by the research of other SuMaRiO sub-projects, where in particular the agricultural project described in Sect. 4.3. is of importance. In order to determine the benefits of the restoration and maintenance of the natural vegetation along the Tarim River, CVM surveys were conducted in summer 2013.

The overall social benefits from a large-scale environmental project in an ecological sensitive region apply not only to the people at the location, but also in other parts of the whole country. That is at least what is to be expected. While the people living there will benefit from an improved wa- 
ter management directly, there are also benefits from such a project which have nothing to do with the direct utilization of the Tarim water and related ecosystem services. Also people living in Beijing care about what is happening in the Tarim River basin and for the living conditions of the local people. From the perspective of Beijing citizens, "desertification" was the most serious environmental problem occurring in the Tarim River basin (see Fig. 14). A possible explanation for this result might be that many parts of China are endangered by desertification. Sandstorms can even be experienced in the city of Beijing (from the Gobi Desert). Therefore, people living in Beijing were also willing to contribute financially to an improvement of the water availability situation in the Tarim River basin.

While environmental improvements in the Tarim Basin would mainly have a direct use value for the local people, it would have a non-use value for the people living far from the Tarim (such as an existence value or a bequest value, when thinking of future generations). Hence, the "long-distance benefits" would also have to be assessed in order to assess the total value of such a project. Neglecting these benefits would lead to a dramatic underestimation of the overall social value obtained from a potential Tarim water management project since many more people live outside the Tarim River basin than within that area. A comprehensive assessment of the project in question would, therefore, require that CVM surveys are conducted all over China which is, of course, unrealistic. Therefore, the study was confined on the one hand to the Tarim region and on the other to the city of Beijing as an example of a region far away from the project site. For an assessment of the overall benefits one would have to think about extrapolating the results from Beijing at least to other big cities in China. This would require the application of benefit transfer techniques which, of course, show a number of weaknesses regarding their validity and reliability as is well-known (see, e.g., Johnston and Moeltner 2014; Kaul et al., 2013; Londoño and Johnston, 2012; Walsh et al., 1992). To assess the preferences of local people, standardized interviews were conducted in different cities of Xinjiang.

The CVM questionnaire was developed by the ChineseGerman research team and continuously adapted based on the results of several waves of pre-tests and the outcomes of multiple citizen expert group meetings in Xinjiang and Beijing. 2438 individuals were interviewed personally using intercept surveys in public locations (parks, squares, cafés, etc.) in urban Beijing. To ensure the representativeness of the data, a quota sampling approach was used. Due to concerns regarding the safety of interviewers and respondents no intercept survey could be realized in Xinjiang. In order to get a sensible assessment of local people's preferences several workshops were organized in Urumqi, Korla, and Lop Nor in July 2013. Workshop participants were recruited via a snowball sampling approach, i.e., local project partners invited their friends and asked them to tell their friends, relatives, and colleagues to join the workshops. Clearly, no represen-

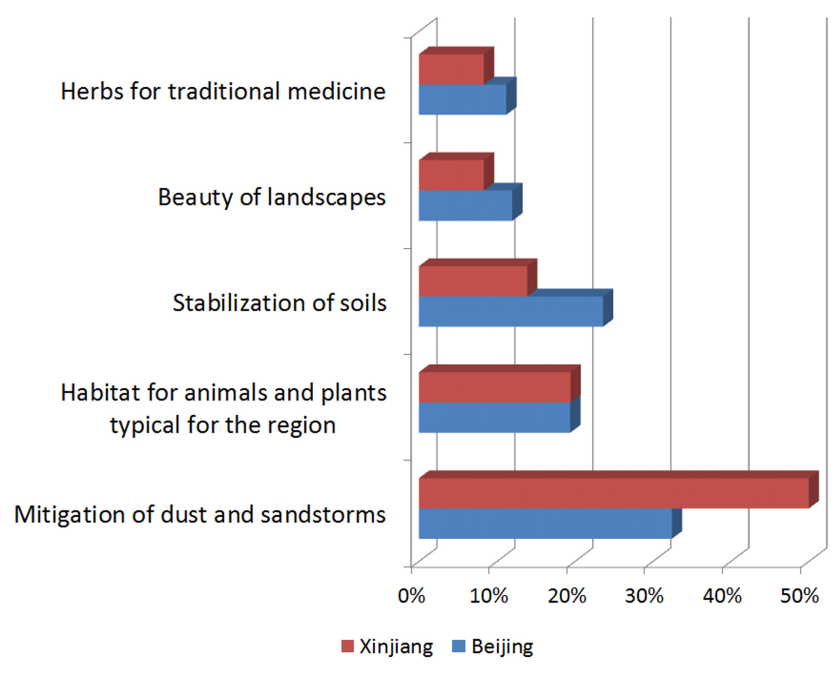

Figure 13. Average citizen's opinion on the restoration and maintenance of the natural environment - importance of ecosystem services provided by the riparian vegetation in the Tarim River basin.

tative sample could be obtained in this way, but the snowball sampling approach appeared to be the only feasible strategy for assessing the preferences of people living in Xinjiang. At the beginning of each workshop the CVM questionnaire was read out in Mandarin or Uighur and completed by the participants. Through this strategy the opinion of 61 local people with diverse demographic backgrounds could be assessed. Some selected characteristics of the survey respondents in the two study sites are displayed in Table 7.

All respondents were asked to express their willingness to pay (WTP) for the implementation of the preservation project. In accordance with economic welfare theory, individual WTP statements can be interpreted as the utility (in monetary terms) a respondent receives from the project in question. If the survey sample was representative of the population affected by such a project, the WTP statements from the sample could be extrapolated to all individuals affected. The mean WTP of the respondents from Xinjiang amounts to $48 \mathrm{RMB}$ per month, corresponding to approximately $1 \%$ of an average respondent's monthly disposable household income (4731 RMB). Respondents from Beijing had a mean WTP of $107 \mathrm{RMB}$, which is also about $1 \%$ of an average respondent's monthly disposable household income (8487 RMB). According to these results, the appreciation of the preservation project in the Tarim River basin is approximately the same at both study sites. Of course, the gathered data are not representative for the Chinese population as a whole; therefore, these WTP estimates cannot be extrapolated to all individuals affected. Apart from the WTP for the preservation project, people's opinion on different aspects of environmental preservation in the Tarim River basin was also assessed. Respondents were asked to rank several ecosystem services (ESS) provided by the natural vegetation 


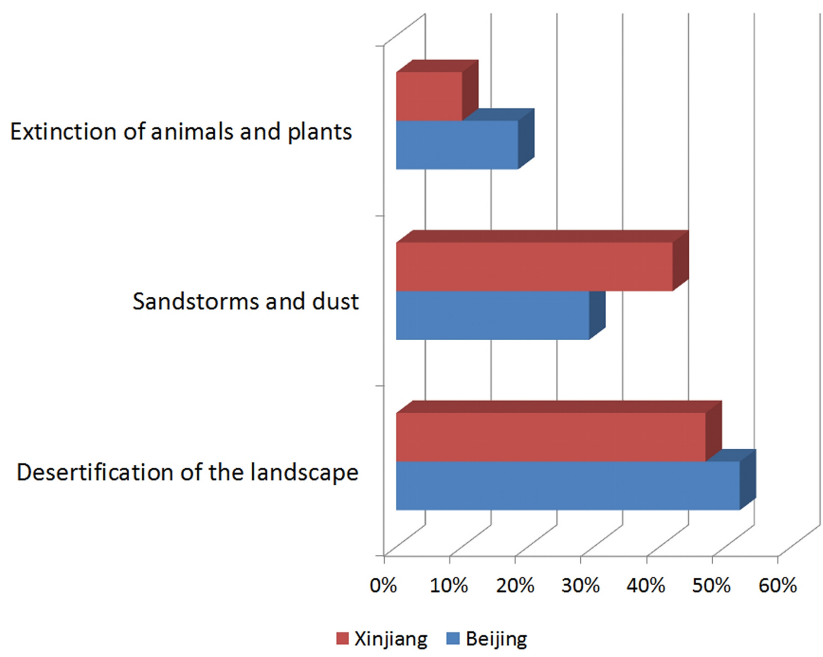

Figure 14. Average citizen's opinion on the restoration and maintenance of the natural environment - seriousness of environmental problems occurring in the Tarim River basin.

in the Tarim River basin according to their importance for society. In addition to that they also had to judge the seriousness of several environmental problems in the Tarim River basin. The results are displayed in Figs. 13 and 14. The preferences for the different ESS turned out to be quite similar at both study sites. Respondents from Xinjiang and from Beijing considered the mitigation of dust and sandstorms as the most important ESS, and the provision of herbs for traditional medicine was perceived as least important. Also the ranking of environmental problems in the Tarim River basin was the same at both study sites. Desertification of the landscape was considered most serious, followed by sandstorms and dust, and the extinction of plants and animals was ranked least important.

The survey results show that also people living far away from the project site appreciate the benefits of environmental preservation in the Tarim River basin as much as local people do. Therefore, confining valuation surveys to the local population only might lead to a systematic undervaluation of environmental improvements and thus to a potential rejection of a socially beneficial project by political decision makers.

\subsection{Transdisciplinary research}

Transdisciplinary research is an iterative and recursive process, which requires continuous reflection and adaption, as new knowledge emerges and is brought into such a consortium like SuMaRiO. The approach to transdisciplinary research here has in overall improved knowledge integration among multiple disciplines and enabled, although partially, knowledge integration from inside and outside of academia. The integration of existing knowledge, which takes stakeholder perspectives and needs into account, is essential for the development of a usable decision support tool (DST) as
Table 7. Demographic characteristics of the survey samples.

\begin{tabular}{|c|c|c|}
\hline Variable & $\begin{array}{l}\text { Xinjiang }{ }^{1} \\
N=61 \\
\text { Mean } \\
\text { (std. } \\
\text { deviation) }\end{array}$ & $\begin{array}{l}\text { Beijing }^{2} \\
N=2438 \\
\text { Mean } \\
\text { (std. } \\
\text { deviation) }\end{array}$ \\
\hline Sex $($ male $=1 ;$ female $=0)$ & $\begin{array}{l}0.557 \\
(0.500)\end{array}$ & $\begin{array}{l}0.504 \\
(0.500)\end{array}$ \\
\hline Age & $\begin{array}{l}39.7 \\
(8.9)\end{array}$ & $\begin{array}{l}40.2 \\
(15.4)\end{array}$ \\
\hline Ethnicity $($ Han $=1 ;$ other $=0)$ & $\begin{array}{l}0.350 \\
(0.481)\end{array}$ & $\begin{array}{l}0.919 \\
(0.273)\end{array}$ \\
\hline Native from Xinjiang/Beijing $($ yes $=1 ;$ no $=0)$ & $\begin{array}{l}0.754 \\
(0.434)\end{array}$ & $\begin{array}{l}0.366 \\
(0.482)\end{array}$ \\
\hline $\begin{array}{l}\text { Education (university degree }=1 \text {; } \\
\text { high school degree or lower }=0 \text { ) }\end{array}$ & $\begin{array}{l}0.738 \\
(0.044)\end{array}$ & $\begin{array}{l}0.382 \\
(0.486)\end{array}$ \\
\hline Monthly disposable income (in $1000 \mathrm{RMB}$ ) & $\begin{array}{l}4.721 \\
(3.700)\end{array}$ & $\begin{array}{l}8.485 \\
(8.485)\end{array}$ \\
\hline
\end{tabular}

${ }^{1}$ As compared to official estimates (see, e.g., Xinjiang Statistical Yearbook 2011) elderly people and Han Chinese are underrepresented, while people with university degrees and higher incomes are overrepresented in the sample. ${ }^{2}$ The collected data closely resembles the official data in terms of people's sex, age, ethnic and local background, and education. Mean disposable income is significantly higher than the official estimate of 7732 RMB (see, e.g., Beijing Statistical Yearbook 2012)

well as identification of actually implementable land and water management strategies that aim at maximizing ecosystem services in the Tarim River basin.

\subsection{Decision support tool}

The key resource of the Tarim River basin is water, which anthropogenic activities and natural ecosystems compete over. Water is delivered from the headwaters of the Aksu River with currently increasing runoff. The competition for water however has not eased mainly because new land for agriculture, which depends entirely on irrigation, has been reclaimed at a high speed. Furthermore, it is unclear how the runoff from the Aksu headwaters could develop in the course of climate change so that no weakening of the water competition can be expected from the supply side. Therefore, a sound allocation of water must be established in order to balance the water competition on the demand side.

This interdisciplinary project will therefore deliver a decision support tool (DST), built on the participation of regional stakeholders and models based on results and field experiments from the data collection phase. This DST finally shall assist stakeholders in balancing water competition, acknowledging the major external effects of any water allocation. However, the complexity of the project cannot fully be implemented in a DST, as the DST has to be understood and used by all kinds of stakeholders with different backgrounds. The simplicity of the DST will help them to understand the greater ecological system of the Tarim River basin. The DST is based on simple rules, which can be modified with new relevant data by every stakeholder according to his/her special 
background; if stakeholders do not have a specific data set, e.g., future climate data, they can still use the given one in the DST, which will give a more accurate picture of the system. Through this DST the SuMaRiO project brings a new kind of decision support to the region, and will help to foster sustainable development.

In the process of developing the decision support tool, the multi-level stakeholder dialogues (MLSDs) were an important tool to implement project results. With its help, important indicators for the definition of climate and socioeconomic scenarios and management alternatives have been designed. Also, representative indicators for all relevant ecosystem services have been identified and weighted for the presentation of land and water management consequences. These results form the basis of the DST.

The workflow of the DST is as follows:

- In the first step, 3 different planning years for the climate and socioeconomic scenarios and management alternatives can be chosen arbitrarily. For each of these years, the DST user can define up to three different climate and socioeconomic scenarios by choosing assumed values for explaining indicators such as an increase in world market cotton price or an increase in average daily temperature. Optionally the user can decide on probabilities for the realization of the scenarios defined before.

- In the second step, up to ten management alternatives can be planned for the upper, middle, and lower reaches of the Tarim River basin for the three different years. Alternatives differ, for example, in the amount of water that is assigned to the different regions or the percentage of land that can be used for agriculture.

- In the third step, the weight of the ecosystems' agriculture (which includes economic benefits), and the (virtual) value of riparian forests, grassland, and urban vegetation can be obtained, just as with the corresponding ecosystem services and the representative indicators. The DST recommends choosing settings from the stakeholder dialogues but the user can overrule this. Furthermore, the side-constrained multi-criteria goals of land and water managers can be defined; for example, one goal could be to maximize the water quality and at the same time maximize the benefit of cotton production. As a side constraint, a minimal virtual value of riparian forests has to be guaranteed.

The first three steps constitute the input phase and are followed by the computation and the analysis phase. In the fourth step, the short- and long-term consequences of each management alternative are calculated in quantitative and semi-quantitative ways for each part of the Tarim River basin. Here "consequences" mean the development/change of the different indicators. This development/change is computed on the basis of the knowledge and models developed within the SuMaRiO project. For some computations fuzzy logic is employed. With the help of the defined goals for each representative ecosystem indicator, a standardized utility value or standardized goal achievement value can be calculated. Based on the standardized utility value, a comparison of each indicator with the result of the current year is made possible. If the alternative generates an improvement or a decline in the standarized utility value of the indicator, this will become apparent in the comparison. With the aggregation of the utility values to a significant value, in terms of utility analysis, all planned management alternatives can be compared with one another and this forms the first part of the output. In addition, the DST performs sensitivity analyses by modifying earlier crucial parameters of the chosen management alternatives. This yields more insight in the allocation problem and forms the last step of the DST process.

\section{Major findings and conclusions}

The combination of scientific findings of an interdisciplinary project like SuMaRiO is quite challenging. Scientists from various disciplines have different foci within the geographic region; even the language and definitions of commonly used terms have to be clarified among the different fields of research and an interdisciplinary definition must be found. In the SuMaRiO project, another difficulty is the three different cultural backgrounds of the scientists involved - German, Chinese, and Uighur. The point of views on specific research topics, scientific methods, and means of communication are different. To find common ground between the interdisciplinary and intercultural project members, communication is the only way to avoid and clear up misunderstandings. The main communication platform of SuMaRiO is the project's official and internal web page. The description of the project, the goals of every work block, and the detailed work plan can be found there in the project's main languages, German, English, and Chinese. Exchange of data and access to reports and the project's publications is undertaken via the internal web page.

Nevertheless, the main and most efficient way to exchange ideas and solve misunderstandings between disciplines and cultures is personal communication in workshops, conferences in Germany and China, and also via telephone or Skype. Another important way to improve intercultural cooperation is for one to spend time in a foreign country, which gives a better understanding of how work is done in other cultures. Trust and motivation for interdisciplinary and intercultural cooperation was strengthened by informal gatherings.

For future cooperation between German and Chinese institutions and to foster stronger relationships among the scientists involved, the common platform called Sino-German Joint Research Center for the Management of Ecosystems and Environmental Changes in Arid Lands (MEECAL) was 
established. It provides the basis for exchange on topics of arid lands and related ecosystems - with a special focus on Xinjiang.

The results of the SuMaRiO project will be archived by the MEECAL platform (http://sinogermanmeecal.de) and will help with the further use of the data. For the implementation of the project results, Chinese stakeholders were involved from the beginning of the project to provide input on specific issues on land use and water management in the region. In the upcoming implementation phase of the project, workshops will be held to train the next generation of local stakeholders on the decision support tool, to convey the findings of the project, and to encourage better understanding between the different cultures involved in the project.

Due to climate change, the melting of glaciers and snow in the surrounding mountains will increase. Thus, the river runoff of the Tarim River will increase in the near future. This increase in water availability may motivate agricultural producers along the Aksu River and upper reaches of the Tarim River to further increase their production area. This may then result in an even stronger aggravation of water shortages and salinity-related problems under the projected decrease in river runoff in the distant future.

With the predicted expansion of the agricultural area in the upper reaches, more cotton will be produced. However, the cultivation of cotton in soils with high salinity, which is likely to occur as arable land is encircled by desert and already degraded soils, reduces water-use efficiency since much irrigation water is needed for leaching salts out of the root zone. This increases water consumption in the upper reaches of the Tarim River and leads to water shortage in middle and lower reaches.

This conflict between the upper and the lower reaches of the Tarim River already exists. The Chinese government reacted to this conflict with the Ecological Water Diversion, by which water from upstream is channeled through the midstream river section to the downstream river section. Additionally, water from Bosten Lake and Kenqi River is transferred into the lower reaches of the Tarim River (Peng et al., 2014). The aim of these water diversions is the preservation of riparian forests, especially Populus euphratica trees, which play an important role in fighting desertification in the region.

The evaluation of satellite images showing the recovery of Populus euphratica trees confirms the assumption that the long-term ecological restoration of degraded riparian Tugai forests along the lower reaches of the Tarim River has had a beneficial influence on $P$. euphratica growth. The detected expansion of aboveground green biomass corresponds to natural succession and suggests improved groundwater conditions after Ecological Water Diversion from 2000 to 2011 (Zhandong et al., 2009).

The reason for the expansion of Populus euphratica trees lies in their manner of natural regeneration. Under given climatic conditions, $P$. euphratica stand development from seedlings is only possible along rivers, in river beds, or after flooding events, when the upper soil has been thoroughly wetted and the distance to groundwater is short enough to be bridged by rapid vertical root growth (Runge, 2004; Thomas, 2014). Thereafter, the distance to the groundwater may become longer through the lowering of the water table (due to groundwater use by the human population or by natural shifts in the course of a river) or by sand accumulation. In some phreatophytic species (species who rely on access to groundwater), including $P$. euphratica, root and shoot growth can keep pace with an increase in the distance to the groundwater and, thus, the trees are capable of maintaining contact with the water, provided that the decrease in the groundwater level is not too rapid and the distance to the groundwater does not become too long. Due to a continuous increase of the groundwater distance, the canopies of $P$. euphratica eventually are positioned at a distance of much more than $10 \mathrm{~m}$ above the water table without losing contact with groundwater (Gries et al., 2003). This process explains the occurrence of phreatophytic vegetation at sites long distances from the water table. At such sites, however, natural generative rejuvenation of the stands is not possible any more, and vegetative regeneration by root suckers (e.g., Wiehle et al., 2009) as well as shoot growth can be hampered by a decrease in hydraulic conductance from the soil to the leaves (Gries et al., 2003). Thus, the density of $P$. euphratica stands will decrease with increasing distance to the water table and increasing age and, eventually, the stands will die off (Runge, 2004).

Our results indicate that in the Tugai forests, the stem diameter increment of Populus euphratica decreases with an increase in tree age and distance to the groundwater. As tree age and groundwater distance are interrelated in the life history of the stands, it is difficult to separate the effects of these two factors from each other. According to previous studies, however, basal area increment of $P$. euphratica also decreases along a gradient of groundwater distances from 7 to $23 \mathrm{~m}$ in trees that exhibit similar basal areas; in those trees, longer distances from the tree crown to the water table were brought about by shifting sand dunes and subsequent stem elongation (Gries et al., 2003). The decrease in basal area increment of those trees could be attributed to a decrease in the leafspecific hydraulic conductance on the flow path from the soil to the leaves, which was also related to the leaf water potential and the stomatal conductance of the leaves (Gries et al., 2003). Thus, it can be assumed that along our study plots near Yingbazar, groundwater distance rather than tree age is the principal reason for the differences in stem diameter increments. Impairment of shoot growth due to wood harvest by the local population, which plays an important role at several locations along the Tarim River, can be excluded as a major influencing factor of shoot growth because our study plots either belong to protected nature reserves (plot GD1) or are located at relatively long distances from the small villages in that region (plots GD2 and GD3). 
The fact that only the poplars in the plot with the short groundwater distance, not the trees growing at longer distances to the water table, exhibited a significant correlation between the standardized stem diameter increment and the preceding year's river runoff might be somewhat surprising at first glance. However, similar results have also been obtained in studies on other phreatophytic species. Sapling mortality of the riparian tree species Populus fremontii and Salix gooddingii was higher at a site with less of a distance to the groundwater, but with a more severe interannual decline of the water table than at a site with a longer distance to the water table, but less change between years (Shafroth et al., 2000), concluding that a constant long distance to the water table is not as severe to sapling mortality as a heavily fluctuating low water table over the years. In that study, the differences in sapling mortality were attributed to the conditions under which the roots were formed.

In conclusion, our results provide further evidence that a longer distance to the groundwater results in reduced stem growth; thus, they are in accordance with the findings of several other studies on woody phreatophytes (see Thomas, 2014). The sensitive growth response of the trees in plot GD1 to changes in the water supply via the Tarim River should be taken into consideration in the future planning of water distribution on a landscape scale; the negative effects of diverting water from sites with a short distances to the water table to sites with longer distances to the groundwater might outweigh any positive effect on $P$. euphratica stands that are already growing at longer distances to the water table and exhibit low productivity regardless. However, a further decline of the water table should also be avoided in those stands in order to prevent further decline of riparian forests, which is already widespread, especially in the lower reaches of the Tarim River (e.g., Feng et al., 2005).

In combination with the results obtained by the hydrological working groups and on the basis of modeling approaches for the future runoff of the Tarim River under projected climatic change, future growth increments of the P. euphratica stands growing at short distances to the groundwater can be estimated and predictions on the productivity of the stands under different scenarios of future river runoff can be developed.

The simulation of future water availability and the development of runoff scenarios for the region support decision makers in managing water and land in the region. Additionally, the assessment of the overall social value of a project contributing to the restoration and protection of the ecosystem services along the Tarim River for all people directly or indirectly (e.g., emotionally) affected in terms of their willingness to pay for that project is helpful to politicians for two reasons. On the one hand, they can compare social costs and benefits using the same measuring units, i.e., money, in order to decide if the realization of such a project is socially profitable and, therefore, advisable or not. In this use the CVM is a political decision tool. On the other hand, the aggregate willingness to pay (WTP) of the winners of such a project can be included in a system of payments for ecosystem services (PES), where those who receive the benefits from ecosystem services make compensation payments according to their preferences to those who provide these benefits (see, e.g., Ahlheim and Neef, 2006). In this use the CVM is also an instrument for the practical implementation of environmental projects since it helps financing such projects in an efficient and also equitable way: the overall sum WTP is an indicator of the extent to which the beneficiaries of an environmental project wish to see an improvement in the provision of the ecosystem services in question (efficiency aspect). If the individual beneficiaries would be forced to pay according to their individual WTP, which reflects the utility gain they expect from that project in monetary terms, such payments would also be equitable considering the equivalence principle of public finance theory.

Acknowledgements. We thank the German Federal Ministry of Education and Research for the funding of the SuMaRiO consortium as part of the Land Management Program, Sustainable Management. Furthermore, we thank the PT-DLR for their constant administrative support and colleagues from the GLUES project for their cooperation. The MODIS vegetation index data sets (MOD13Q1 product, collection 5) used in this work were obtained through the online Data Pool at the NASA Land Processes Distributed Active Archive Center (LP DAAC), USGS Earth Resources Observation and Science (EROS) Center, Sioux Falls, South Dakota, USA (https://lpdaac.usgs.gov/dataaccess).

Edited by: V. Lucarini

\section{References}

Ahlheim, M. and Neef, A.: Payments for environmental services, tenure security and environmental valuation: concepts and policies towards a better environment, Q. J. Int. Agr., 45, 303-318, 2006.

Becker, A., Finger, P., Meyer-Christoffer, A., Rudolf, B., Schamm, K., Schneider, U., and Ziese, M.: A description of the global land-surface precipitation data products of the Global Precipitation Climatology Centre with sample applications including centennial (trend) analysis from 1901-present, Earth Syst. Sci. Data, 5, 71-99, doi:10.5194/essd-5-71-2013, 2013.

Bohnet, A., Giese, E., and Zeng, G.: Die Autonome Region Xinjiang (VR China) - Eine ordnungspolitische und regionalökonomische Studie (Band I), LIT Verlag, Münster, Hamburg, London, 1998.

Bohnet, A., Giese, E., and Zeng, G.: Die Autonome Region Xinjiang (VR China) - Eine ordnungspolitische und regionalökonomische Studie (Band II), LIT Verlag, Münster, Hamburg, London, 1999.

CAWA: Regional Research Network - Central Asian Water, http: //www.cawa-project.net/ (last access: 5 March 2015), 2013.

Chen, Y. N., Li, W. H., Xu, C. C., and Hao, X. M.: Effects of climate change on water resources in Tarim River Basin, North- 
west China, J. Environ. Sci., 19, 488-493, doi:10.1016/S10010742(07)60082-5, 2007.

Chiriacy-Wantrup, S. V.: Natural Resource Economics, in: Selected Papers, Westview Press, Boulder, 1985.

Decagon: 10HS Soil Moisture Sensor Manual, Decagon Devices, Inc, Pullman, WA, USA, 2014.

ELD: Economics of Land Degradation (ELD) Initiative - A Global Initiative to Raise Awareness of the Economic Losses Arising from Land Degradation. Interim Report, United Nations University, Institute for Water, Environment, and Health, Hamilton, Ontario, Canada, 2013.

Eppink, F., Werntze, A., Mäs, S., Popp A., and Seppelt, R.: Landmanagement and Ecosystem Services. How collaborative research programmes can support better policies, GAIA 21/1, oekom Verlag, Munich, 55-63, 2012.

FAOSAT: FAO Statistical Yearbook 2012, Food and agriculture organization of the United Nations, FAO, Rome, 2012.

Feike, T., Mamitimin, Y., Li, L. and Doluschitz, R.: Development of agricultural land and water use and its driving forces along the Aksu and Tarim River, P.R. China, Environ. Earth Sci. (in press), 2014.

Feng, Q., Liu, W., Si, J. H., Su, Y. H,, Zhang, Y. W., Cang, Z. Q., and Xi, H. Y.: Environmental effects of water resource development and use in the Tarim River basin of northwestern China, Environ. Geol., 48, 202-210, 2005.

Gärtner, P., Förster, M., Kurban, A., and Kleinschmit, B.: Object based change detection of Central Asian Tugai vegetation with very high spatial resolution satellite imagery, Int. J. Appl. Earth Obs. Geoinf., 31, 110-121, doi:10.1016/j.jag.2014.03.004, 2014.

Giese, E., Bahro, G., and Betke, D.: Umweltzerstörungen in Trockengebieten Zentralasiens (West- und Ost-Turkestan). Ursachen, Auswirkungen, Maßnahmen, Erdkundliches Wissen, Band 125, F. Steiner Verlag, Stuttgart, p. 189, 1998.

Glazirin, G. E.: A century of investigations on outbursts of the icedammed Lake Merzbacher (Central Tien Shan), Aust. J. Earth Sci., 103, 171-179, 2010.

GLUES Geoportal - Global Assessment of Land Use Dynamics on Greenhouse Gas Emissions and Ecosystem Services: http://geoportal.glues.geo.tu-dresden.de/index.php, last access: 22 July 2014.

Gowda, P. H., Chavez, J. L., Colaizzi, P. D., Evett, S. R., Howell, T. A., and Tolk, J. A.: Remote sensing based energy balance algorithms for mapping ET: current status and future challenges, Am. Soc. Agric. Biol. Eng., 50, 1639-1644, 2007.

Gowda, P. H., Chavez, J. L., Colaizzi, P. D., Evett, S. R., Howell, T. A., and Tolk, J. A.: ET mapping for agricultural water management: present status and challenges, Irrig. Sci., 26, 223-237, 2008.

Grashey-Jansen, S. and Timpf, S.: Soil Hydrology of Irrigated Orchards and Agent-Based Simulation of a Soil Dependent Precision Irrigation System, Adv. Sci. Lett., 3, 259-272, 2010.

Grashey-Jansen, S., Kuba, M., Cyffka, B., Halik, Ü., and Aishan, T.: Spatio-temporal Variability of Soil Water at Three Seasonal Floodplain Sites: A Case Study in Tarim Basin, Northwest China, Chinese Geogr. Sci., 24, 647-657, doi:10.1007/s11769014-0717-y, 2014.

Gries, D., Zeng, F., Foetzki, A., Arndt, S. K., Bruelheide, H., Thomas, F. M., Zhang, X., and Runge, M.: Growth and water relations of Tamarix ramosissima and Populus euphratica on Tak- lamakan desert dunes in relation to depth to a permanent water table, Plant Cell Environ., 26, 725-736, 2003.

Han, D., Song, X., Currell, M. J., Cao, G., Zhang, Y., and Kang, Y.: Monitoring of soil salinization in Northern Tarim Basin, Xinjiang of China in dry and wet seasons based on remote sensing, J. Hydrol., 405, 217-234, 2011.

Harris, I., Jones, P. D., Osborn, T. J., and Lister, D. H.: Updated high-resolution grids of monthly climatic observations - the CRU TS3.10 Dataset, Int. J. Climatol., 34, 623-642, doi:10.1002/joc.3711, 2014.

Hoppe, T., Kleinschmit, B., Roberts, B., Thevs, N., and Halik, Ü. (Eds.): Watershed and Floodplain Management along the Tarim River in China's Arid Northwest, Shaker, Aachen, 2006.

Huete, A., Didan, K., Miura, T., Rodriguez, T., Gao, X., and Ferreira, F.: Overwiew of the Radiometric and Biophysical Performance of the MODIS Vegetation Indices, Remote Sens. Environ., 83, 195-213, 2002.

IUSS Working Group WRB: World Reference Base for Soil Resources 2006, World Soil Resources Reports No. 103, FAO, Rome, 2006.

Johnston, R. J. and Moeltner, K.: Meta-Modeling and Benefit Transfer: The Empirical Relevance of Source-Consistency in Welfare Measures, Environ. Resour. Econ., 59, 337-361, doi:10.1007/s10640-013-9730-3, 2014.

Kaul, S., Boyle, K. J., Kuminoff, N. V., Parmeter, C. F., and Pope, J. C.: What can we learn from benefit transfer errors? Evidence from 20 years of research on convergent validity, J. Environ. Econ. Manage., 66, 90-104, 2013.

Keilholz, P.: Auswirkungen von veränderter Landnutzung auf den Wasserhaushalt und die Auwaldvitalität in einer Flussoase am Tarim (China), PhD thesis, Technical University Munich, Munich, 2014.

Krysanova, V., Wortmann, M., Bolch, T., Merz, B., Duethmann, D., Walter, J., Huang, S., Jiang, T., Su, B., and Kundzewicz, Z.: Analysis of current trends in climate parameters, river discharge and glaciers in the Aksu River basin (Central Asia), Hydrolog. Sci. J., doi:10.1080/02626667.2014.925559, in press, 2014.

Kundzewicz, Z., Merz, B., Vorogushyn, S., Hartmann, H., Duethmann, D., Wortmann, M., Huang, S., Su, B., Jiang, T., and Krysanova, V.: Analysis of changes in climate and river discharge with focus on seasonal runoff predictability in the Aksu River Basin, Environ. Earth Sci., 73, 501-516, doi:10.1007/s12665014-3137-5, 2014.

Londoño, L. M. and Johnston, R. J.: Enhancing the reliability of benefit transfer over heterogeneous sites: A meta-analysis of international coral reef values, Ecol. Econ., 78, 80-89, 2012.

Malek, E. and Bingham, G. E.: Comparison of the Bowen ratioenergy balance and the water balance methods for the measurement of evapotranspiration, J. Hydrol., 146, 209-220, 1993.

Mamitimin, Y., Feike, T., Seifert, I., and Doluschitz, R.: Irrigation in the Tarim Basin, China: farmers' response to changes in water pricing practices, Environ. Earth Sci., 73, 559-569, doi:10.1007/s12665-014-3245-2, 2014.

MEA - Millennium Ecosystem Assessment: Ecosystems and Human Well-being: Synthesis, Island Press, Washington, D.C., 2005.

Meinshausen, M., Smith, S. J., Calvin, K., Daniel, J. S., Kainuma, M. L. T., Lamarque, J. F, Matsumoto, K., Montzka, S. A., Raper, S. C. B., Riahi, K., Thomson, A., Velders, G. J. M., and Vuuren, 
D. P. P.: The RCP greenhouse gas concentrations and their extensions from 1765 to 2300, Climatic Change, 109, 213-241, 2011.

Mitchell, R. C. and Carson, R. T.: Using Surveys to Value Public Goods - the Contingent Valuation Method, Resources for the Future, Washington, D.C., 1989.

Mitchell, T. D. and Jones, P. D.: An improved method of constructing a database of monthly climate observations and associated high-resolution grids, Int. J. Climatol., 25, 693-712, 2005.

Municipal Government of Aksu: Akesu shi chuangjian guojia senlin chengshi shenbao cailiao (declaration data for creating state forest city of Aksu), Aksu, 2007.

NBSCa: Statistical Yearbooks of Xinjiang, Urumqi, 1990-2012.

NBCSb: Xinjiang Construction and Production Corps, Urumqi, 1990-2012.

Ng, F., Liu, S., Mavlyudov, B., and Wang, Y.: Climatic control on the peak discharge of glacier outburst floods, Geophys. Res. Lett., 34, L21503, doi:10.1029/2007GL031426, 2007.

OAI-PMH: Open Archives Initiative Protocol for Metadata Harvesting, Protocol Version 2.0 of 2002-06-14, Document Version 2008-12-07T20:42:00Z: http://www.openarchives.org/OAI/ 2.0/openarchivesprotocol.htm, last access: 22 July 2014.

OGC: OGC Standards and Supporting Documents, Open Geospatial Consortium: http://www.opengeospatial.org/standards, last access: 22 July 2014.

Orlowsky, B., Gerstengarbe, F.-W., and Werner, P. C.: A resampling scheme for regional climate simulations and its performance compared to a dynamical $\mathrm{rcm}$, Theor. Appl. Climatol., 92, 209-223, 2008.

Osmonov, A., Bolch, T., Xi, C., Kurban, A., and Guo, W.: Glacier characteristics and changes in the Sary-Jaz River Basin (Central Tien Shan) 1990-2010, Remote Sens. Lett., 4, 725-734, doi:10.1080/2150704X.2013.789146, 2013.

Peng, H., Thevs, N., and Ott, K.: Water Distribution in the perspectives of stakeholders and water users in the Tarim River catchment, Xinjiang, China, J. Water Resour. Protect., 6, 543-555, doi:10.4236/jwarp.2014.66053, 2014.

Rinn, F.: Time series analysis and presentation for dendrochronology and related applications V0.53, User Reference, Rinntech, Heidelberg, 2003.

Rockel B., Will, A., and Hense, A.: The regional climate model COSMO-CLM (CCLM), Meteorol. Z., 17, 347-348, 2008.

Roerink, G. J., Su, B., and Menenti, M.: S-SEBI A simple remote sensing algorithm to estimate the surface energy balance, Phys. Clim. Earth B, 25, 147-157, 2000.

Runge, M.: Ecological basis for a sustainable management of the indigenous vegetation in a Central Asian desert: conclusions derived from project results, in: Ecophysiology and Habitat Requirements of Perennial Plant Species in the Taklimakan Desert, edited by: Runge, M. and Zhang, X., Shaker, Aachen, 161-170, 2004

Schneider, U., Becker, A., Meyer-Christoffer, A., Ziese, M., and Rudolf, B.: Global precipitation analysis products of the GPCCRep., Deutscher Wetterdienst, Offenbach a. M., Germany, 2011.

Schroeder, M. and Wächter, J.: A Scientific SDI Node for Sustainable Land and Water Management, Pre-conference workshop: Testing Geospatial Web Services - Scientific SDIs, 15th AGILE International Conference on Geographic Information Science, 24 April 2012, Avignon, France, 2012.
Schroeder, M., Stender, V., Klump, J., Kunkel, R., and Wächter, J.: The Design of Monitoring and Data Infrastructures - Applying a forward-thinking Reference Architecture, IEEE International Conference on Networking, Sensing and Control, Paris, 2013.

Shafroth, P. B., Stromberg, J. C., and Patten, D. T.: Woody riparian vegetation response to different alluvial water table regimes, West N. Am. Nat., 60, 66-76, 2000.

Shangguan, D. H., Liu, S. Y., Ding, Y. J., Ding, L. F., Xu, J. L., and Jing, L.: Glacier changes during the last forty years in the Tarim Interior River basin, northwest China, J. Prog. Nat. Sci., 19, 727-732, 2009.

Shen, Y. and Lein, H.: Treating water as an economic good: policies and practices in irrigation agriculture in Xinjiang, China, Geogr. J., 176, 124-137, 2010.

Siew, T. F. and Döll, P.: Transdisciplinary research for supporting the integration of ecosystem services into land and water management in the Tarim River Basin, Xinjiang, China, J. Arid Land, 4, 196-210, 2012.

Siew, T. F., Döll, P., and Yimit, H.: Experiences with a transdisciplinary research approach for integrating ecosystem services into water management in Northwest China, in: The Global Water System in the Anthropocene, edited by: Bhaduri, A., Bogardi, J., Leentvaar, J., and Marx, S., Springer International Publishing Switzerland, 303-319, doi:10.1007/978-3-319-07548-8_20, 2014.

Sobrino, J. A., Gómez, M., Jiménez-Muñoz, J. C., and Olioso, A.: Application of a simple algorithm to estimate daily evapotranspiration from NOAA-AVHRR images for the Iberian Peninsula, Remote Sens. Environ., 110, 139-148, 2005.

Sobrino, J. A., Gómez, M., Jiménez-Muñoz, J. C., Olioso, A., and Chehbouni, G.: A simple algorithm to estimate evapotranspiration from DAIS data: Application to the DAISEX campaigns, J. Hydrol., 315, 117-125, 2007.

Song, Y. D., Fan, Z. L., Lei, Z. D., and Zhang, F .W.: Research on Water Resources and Ecology of the Tarim River, China, Xinjiang Peoples Press, Urumqi, 2000.

Stender, V., Ulbricht, D., Schroeder, M., and Klump, J.: Automatic publishing ISO 19115 metadata with PanMetaDocs using SensorML information, id.2597, EGU General Assembly 2014, held: 27 April-2 May 2014, Vienna, Austria, 2014.

Steppeler J., Doms, G., Schättler, U., Bitzer, H. W., Gassmann, A., Damrath, U., and Gregoric, G.: Meso-gamma scale forecasts using the nonhydrostatic model LM, Meteorol. Atmos. Phys., 82, 75-96, 2003.

SuMaRiO Webportal, http://www.sumario.de/project, last access: 31 December 2014.

Tao, H., Gemmer, M., Bai, Y., Su, B., and Mao, W.: Trends of streamflow in the Tarim River Basin during the past 50 years: human impact or climate change?, J. Hydrol., 400, 1-9, doi:10.1016/j.jhydrol.2011.01.016, 2011.

TEEB: The Economics of Ecosystems and Biodiversity Ecological and Economic Foundations. Edited by Pushpam Kumar, Earthscan, London, Washington, 2010.

Thevs, N., Zerbe, S., Peper, J., and Succow, M.: Vegetation and vegetation dynamics in the Tarim River floodplain of continentalarid Xinjiang, NW China, Phytocoenologia, 38, 65-84, $2008 \mathrm{a}$.

Thevs, N., Zerbe, S., Schnittler, M., Abdusalih, N., and Succow, M.: Structure, reproduction and flood-induced dynamics of riparian 
Tugai forests at the Tarim River in Xinjiang, NW China, Forestry, 81, 45-57, 2008b.

Thevs, N., Rozi, A., Kubal, C., and Abdusalih, N.: Water consumption of agriculture and natural ecosystems along the Tarim River, China, Geo-Öko, 34, 50-76, 2013.

Thevs, N., Zerbe, S., Peng, H. Y., and Rozi, A.: Water allocation and water consumption of irrigation agriculture and natural vegetation in the Aksu and Tarim river basin, Xinjiang, China, J. Arid Environ., 112, 87-97, doi:10.1016/j.jaridenv.2014.05.028, 2014.

Thomas, F. M.: Ecology of Phreatophytes, in: Progress in Botany, vol. 75, edited by: Lüttge, U., Beyschlag, W., and Cushman, J., Springer, Berlin, 335-375, 2014.

Thomas, F. M., Foetzki, A., Arndt, S. K., Bruelheide, H., Gries, D., Zeng, F. J., Zhang, X. M., and Runge, M.: Water use by perennial plants in the transition zone between river oasis and desert in NW China, Basic Appl. Ecol., 7, 253-267, 2006.

Ulbricht, D., Klump, J., and Bertelmann, R.: Publishing datasets with eSciDoc and panMetaDocs, Geophysical Research Abstracts Vol. 14, EGU2012-7058-2, 2012, General Assembly European Geosciences Union, Vienna, 2012.

Walsh, R. G., Johnson, D. M., and McKean, J. R.: Benefit transfer of outdoor recreation demand studies, 1968-1988, Water Resour. Res., 28, 707-713, 1992.

Wang, D., Menz, C., Simon, T., Simmer, C., and Ohlwein, C.: Regional dynamical downscaling with CCLM over East Asia, Meteorol. Atmos. Phys., 121, 39-53, 2013.

Wang, R. S., Wan, S. Q., Kang, Y. H., and Liu, S. P.: Comparison of Two Dripper Line Designs to Assess Cotton Yield, Water Use, and Net Return in Northwest China, J. Integr. Agr., 11, 19241932, 2012.
Wang, S. J., Chen, B. H., and Li, H. Q.: Euphrates Poplar Forest, China Environmental Science Press, Beijing, 1996.

Wang, Y. (Ed.): Local records of the Akesu River basin, Fangzi Publisher, Beijing, 719 pp., 2006.

Weedon, G. P., Gomes, S., Viterbo, P., Shuttleworth, W. J., Blyth, E., Oesterle, H., Adam, J. C., Bellouin, N., Boucher, O., and Best, M.: Creation of the WATCH Forcing Data and Its Use to Assess Global and Regional Reference Crop Evaporation over Land during the Twentieth Century, J. Hydrometeorol., 12, 823848, doi:10.1175/2011JHM1369.1, 2011

Werner, P. C. and Gerstengarbe, F.-W.: Proposal for the development of climate scenarios, Clim. Res., 8, 171-180, 1997.

Wiehle, M., Eusemann, P., Thevs, N., and Schnittler, M.: Root suckering patterns in Populus euphratica (Euphrates poplar, Salicaceae), Trees, 23, 991-1001, 2009.

Wortmann, M., Krysanova, V., Kundzewicz, Z., Su, B., and Li, X.: Assessing the influence of the Merzbacher Lake outburst floods on discharge using the hydrological model SWIM in the Aksu headwaters, Kyrgyzstan/NW China, Hydrol. Process., 28, 63376350, doi:10.1002/hyp.10118, 2013.

Yao, Y., Ding, J. L., Zhang, F., Wang, G., and Jiang, H. N.: Monitoring of soil salinization in Northern Tarim Basin, Xinjiang of China in dry and wet seasons based on remote sensing, Chinese J. Appl. Ecol., 24, 3213-3220, 2013.

Yatagai A., Kamiguchi, K., Arakawa, O., Hamada, A., Yasutomi, N., and Kitoh, A.: Aphrodite: constructing a long-term daily gridded precipitation dataset for Asia based on a dense network of rain gauges, B. Am. Meteorol. Soc., 93, 1401-1415, 2012.

Zhandong, S., Opp, C., and Run, W.: Vegetation response to Ecological Water Diversion in the lower Tarim River, Xinjiang, China, Basic Appl. Dryland Res., 3, 1-16, 2009. 